Board of Governors of the Federal Reserve System

International Finance Discussion Papers

Number 934

June 2008

Trade Elasticity of Substitution and Equilibrium Dynamics

Martin Bodenstein

NOTE: International Finance Discussion Papers are preliminary materials circulated to stimulate discussion and critical comment. References to International Finance Discussion Papers (other than an acknowledgment that the writer has had access to unpublished material) should be cleared with the author. Recent IFDPs are available on the Web at www.federalreserve.gov/pubs/ifdp/. 


\title{
Trade Elasticity of Substitution and Equilibrium Dynamics*
}

\author{
Martin Bodenstein** \\ Federal Reserve Board
}

June 2008

\begin{abstract}
The empirical literature provides a wide range of estimates for trade elasticities at the aggregate level. Furthermore, recent contributions in international macroeconomics suggest that low (implied) values of the trade elasticity of substitution may play an important role in understanding the disconnect between international prices and real variables. However, a standard model of the international business cycle displays multiple locally isolated equilibria if the trade elasticity of substitution is sufficiently low. The main contribution of this paper is to compute and characterize some dynamic properties of these equilibria. While multiple steady states clearly signal equilibrium multiplicity in the dynamic setup, this is not a necessary condition. Solutions based on log-linearization around a deterministic steady state are of limited to no help in computing the true dynamics. However, the log-linear solution can hint at the presence of multiple dynamic equilibria.
\end{abstract}

Keywords: multiple equilibria, linearization, DSGE models

JEL Classification: C68, F41

** Telephone (202) 452 3796. E-mail Martin.R.Bodenstein@frb.gov.

* I thank Roc Armenter, Christopher Gust, Jonathan Heathcote, and Ricardo Nunes for valuable comments and discussion. I am also grateful to an anonymous associate editor whose suggestions greatly improved this paper. Previously, the paper circulated under the title "Closing Open Economy Models". The views expressed in this paper are solely the responsibility of the author and should not be interpreted as reflecting the views of the Board of Governors of the Federal Reserve System or of any other person associated with the Federal Reserve System. 


\section{Introduction}

General equilibrium theory is plagued with the problem of equilibrium multiplicity. ${ }^{1}$ This paper analyzes a standard model of the international business cycle that is based on the seminal contribution of Backus, Kehoe, and Kydland (1995). If the elasticity of substitution between the home and the foreign good is sufficiently low, this model displays multiple locally isolated equilibria. ${ }^{2}$ The main contribution of this paper is to characterize the dynamic properties of these multiple equilibria in a model with endogenous capital accumulation and incomplete international financial markets for borrowing and lending. The two major computational issues that arise are to identify conditions that indicate the existence of multiple equilibria and to find a reliable method to compute these equilibria.

To build intuition, consider an endowment economy with two countries and two traded goods that are imperfect substitutes. The countries are mirroring each other with respect to preferences and endowments. ${ }^{3}$ There is always one equilibrium with the relative price of the traded goods equal to unity. However, there can be two more equilibria. Let the price of the domestic good be high relative to the price of the foreign good, so that domestic agents have high purchasing power relative to the foreign agents. If the elasticity of substitution is low, foreigners are willing to give up most of their good in order to consume at least some of the domestic good, and domestic agents end up consuming most of the domestic and the foreign good. The reverse is true as well. Foreign agents consume most of the two goods, if the foreign good is very expensive in relative terms. Of course, these last two scenarios cannot be an equilibrium for high values of the elasticity of substitution. In the limiting case

\footnotetext{
${ }^{1}$ See Kehoe (1991).

${ }^{2}$ The equilibrium multiplicity discussed in this paper does not stem from equilibrium indeterminacy as in Benhabib and Farmer (1994).

${ }^{3}$ By mirroring I mean that good 1 (2) enters the utility function of agents in country 1 the same way that good 2 (1) enters the utility function of agents in country 2. The same holds true for agents' endowments with goods 1 and 2 .
} 
of perfect substitutability the unique equilibrium features each country consuming its own endowment. Such a model of multiple locally unique equilibria allows for the construction of sunspot equilibria, meaning there are equilibria for which allocations are different across different states of nature, even though nothing fundamental has changed. ${ }^{4}$

In a model with endogenous state variables the computation of dynamic multiple equilibria cannot be separated from considering sunspot equilibria. To eliminate these complications I conduct the following experiment. In the first period the economy experiences an unforeseen shock to technology. This is the only period in which agents are free to coordinate on any of the possible equilibrium paths. Starting from the second period onwards, agents have perfect foresight and they keep coordinating on the equilibrium path that has been chosen in the first period.

Under these assumptions I can typically find three equilibria provided that the elasticity of substitution is sufficiently low. Along the first equilibrium path the dynamics are solely driven by the impact of the technology shock and all variables stay in the neighborhood of their pre-shock level. The dynamics of the other two equilibria are mostly driven by the shifts in relative purchasing power due to selffulfilling changes in the relative price of the home and foreign good. The effects of the technology shock are negligible in these cases.

Whereas for a given calibration the existence of multiple equilibria mostly depends on the magnitude of the trade elasticity of substitution, it can also depend on the magnitude and the persistence of the shock. In some cases, two of the three equilibria cease to exists if the shock is sufficiently large or permanent. At least in the cases presented in this paper, the now unique equilibrium involves a large shift in relative purchasing power.

Although equilibrium multiplicity in the dynamic model mostly goes along with

\footnotetext{
${ }^{4}$ There is a large literature on sunspot equilibria. Most prominent are the seminal contributions of Cass and Shell (1983) and Azariadis (1981).
} 
multiple steady states, one can also find multiple equilibria in cases with a unique steady state. In a model with a slow-moving capital stock the short-run excess demand function behaves differently from the long-run excess demand, as the economy is less flexible in the short run.

The major challenge in computing equilibria in an environment with multiple locally unique equilibria is to generate a good starting guess. Fortunately, it is possible to derive a starting guess for the model economy with capital and incomplete financial markets from an endowment economy with incomplete financial markets. Using a combination of backward and forward shooting algorithms the impulse response functions for a technology shock are derived under the aforementioned assumption that in the period of the shock agents coordinate once and for all on one equilibrium path.

Linearization or higher-order perturbation methods that approximate the equilibrium policy functions around a deterministic steady state are of limited use in an environment with low trade elasticities. First, these methods can only detect one of the three equilibria. In particular, the method cannot detect those equilibria that are associated with the large shifts in relative purchasing power. Second, in some cases of large shocks local approximation techniques are inappropriate. This issue is not just due to the declining accuracy of the approximation method with increasing distance from the deterministic steady state. The real problem is that the method searches for an equilibrium path where it can be shown that no such equilibrium path exists for a shock of the considered size. Hence, even if one is willing to abstract from equilibrium multiplicity and the possibility of sunspot equilibria, global non-linear methods are preferred to local approximation methods. However, the linear approximation to the policy functions can be put to use in detecting the presence multiple equilibria.

The literature provides a large range of estimates for the trade elasticity of substitution. Using aggregate data Whalley (1995) reports an elasticity of 1.5. In a recent 
study, Hooper, Johnson and Marquez (2000) estimate trade elasticities for the G7 countries. They report a short-run trade elasticity of 0.6 for the U.S. and values between 0 and 0.6 for the remaining G7 countries. Taylor (1993) estimates an import demand equation for the U.S. and finds a short-run elasticity of 0.22 and a long-run trade elasticity of 0.39. Obviously, these macro estimates are in sharp contrasts to the estimates from lower levels of aggregation. In Broda and Weinstein (2005), for example, the mean estimates are between 4 and 6 . Most relevant for this paper, it is common in many applied macroeconomic models to choose values of the elasticity of substitution between 1 and 1.5. Examples include Backus et al (1995), Chari, Kehoe, and McGrattan (2003), and Heathcote and Perri (2002). Recently, however, models with (implied) low elasticities of substitution between home and foreign goods have received considerable attention - Corsetti, Dedola, and Leduc (2008), Collard and Dellas (2004), Benigno and Thoenissen (2008), Thoenissen (2008), and Enders and Mueller (2008) - as such models seem to provide a better fit to the international business cycle. In particular, this has been shown for the case of the puzzling negative correlation between the real exchange rate and relative consumption (Backus and Smith (1993)), cross-country consumption correlations, and the volatility of the real exchange rate. Furthermore, Rabanal and Tuesta (2005) and Lubik and Schorfheide (2005) show estimates for the elasticity of substitution well below unity in DSGE models using Bayesian techniques. In a model that is akin to Corsetti et al (2008), de Walque, Smets and Wouters (2005) find that the data speaks in favor of a low implied elasticity of substitution.

This paper does not take a stand on the value of the trade elasticity of substitution in macro models. However, as there seems to be considerable interest in models with low trade elasticities, it is important to search for tools that allow a complete analysis of models with multiple equilibria and to investigate the extent to which the results of these models and their support through the data hinge on the value of the elasticity of substitution between traded goods being so low that the model 
admits multiple equilibria. ${ }^{5}$

The remainder of the paper is organized as follows. Section 2 introduces the problem of multiple equilibria in a static endowment economy. Section 3 presents a dynamic model with endogenous capital accumulation and international borrowing and lending. Computational issues are addressed in Section 4. In Section 5, the equilibrium multiplicity in the dynamic economy is illustrated with the help of impulse response functions. Some sensitivity aspects of the results are discussed in Section 6. Section 7 concludes.

\section{Multiple Equilibria}

The analysis begins with the well-known example of a static exchange economy with two agents and two goods. ${ }^{6}$ Let agent $i(i=1,2)$ receive an endowment of $y_{i}$ units of good $i$. Agents can trade their endowments with each other and they have constant elasticity of substitution preferences over the two goods. The problem of agent $i$ is given by

$$
\begin{aligned}
& \max _{c_{i 1}, c_{i 2}} c_{i}=\left[\left(\alpha_{i 1}\right)^{1-\rho} c_{i 1}^{\rho}+\left(\alpha_{i 2}\right)^{1-\rho} c_{i 2}^{\rho}\right]^{\frac{1}{\rho}} \\
& \text { s.t. } \\
& \bar{P}_{1} c_{i 1}+\bar{P}_{2} c_{i 2} \leq \bar{P}_{i} y_{i},
\end{aligned}
$$

where $\rho<1$ and $\alpha_{i i} \geq \alpha_{i j}, j \neq i . \varepsilon \equiv \frac{1}{1-\rho}$ is the elasticity of substitution between the two goods. $c_{i j}$ denotes the amount of good $j$ that is consumed by agent $i . \bar{P}_{j}$ is the price of good $j$. Absent trading frictions both agents face the same prices.

\footnotetext{
${ }^{5}$ Corsetti et al (2008), Thoenissen (2008), and de Walque et al (2005) emphasize that there is a critical value of the elasticity of substitution for which the real exchange rate becomes very volatile. At least in the context of the simple model presented in this paper, it can be shown that such a critical point coincides with the appearance of multiple equilibria.

${ }^{6}$ Mas-Colell, Whinston, and Green (1995) and Kehoe (1991) provide an excellent treatment of general equilibrium analysis.
} 
Market clearing requires

$$
\sum_{j=1,2} c_{j i} \leq y_{i}, i=1,2
$$

An equilibrium in this economy is defined as follows.

Definition 1 A competitive equilibrium is an allocation $c_{i j}, i=1,2, j=1,2$ and prices $\bar{P}_{i}, i=1,2$ such that $(i)$ for every agent $i$ the pair $\left(c_{i 1}, c_{i 2}\right)$ solves the problem stated in (1) at the given prices and (ii) all markets clear.

Define $\bar{q}=\frac{\bar{P}_{2}}{\bar{P}_{1}}$, and let $z_{2}$ denote the excess demand for good 2. A competitive equilibrium is then fully summarized by

$$
\begin{aligned}
& z_{2}(\bar{q})=c_{12}(\bar{q})+c_{22}(\bar{q})-y_{2}, \\
& z_{2}(\bar{q}) \leq 0, \bar{q} \geq 0 \text { and } \bar{q} z_{2}(\bar{q})=0 .
\end{aligned}
$$

Since agents' preferences over goods in (1) are strictly monotone, the equilibrium price is strictly positive, and $z_{2}(\bar{q})=0$.

Standard theorems establish the existence of a competitive equilibrium. However, the equilibrium may not be unique. Let index $\left(\bar{q}^{*}\right)=\operatorname{sign}\left(\frac{\partial z_{2}\left(\bar{q}^{*}\right)}{\partial \bar{q}}\right)$ be the index of an equilibrium with the relative price $\bar{q}^{*}$. If all equilibria are locally unique, the sum of the indices across equilibria equals +1 by virtue of the index theorem. Hence, the number of equilibria is finite. If there is an equilibrium with $\frac{\partial z_{2}\left(\bar{q}^{*}\right)}{\partial \bar{q}}>0$, there are at least two more equilibria. ${ }^{7}$

Figure 1 plots the excess demand for good 2 as a function of a monotone transformation of the relative price, $\frac{\bar{q}}{1+\bar{q}}$, for two different values of the elasticity of substitution, $\varepsilon=2$ and $\varepsilon=0.42 .{ }^{8}$ There is a unique equilibrium with $\bar{q}=1\left(\frac{\bar{q}}{1+\bar{q}}=\frac{1}{2}\right)$ for $\varepsilon=2$, but there are three equilibria with $\bar{q}$ equal to $0.47\left(\frac{\bar{q}}{1+\bar{q}}=0.32\right), 1$, and $2.12\left(\frac{\bar{q}}{1+\bar{q}}=0.68\right)$ for $\varepsilon=0.42$. Notice, that in the latter case the slope of the excess

\footnotetext{
${ }^{7}$ See Kehoe (1980) for a discussion of the index theorem.

${ }^{8}$ The parameter values underlying Figure 1 are summarized in Table 1 and discussed in Section 4.3.
} 
demand function is positive for $\bar{q}=1$ and all the equilibria are locally unique. ${ }^{9}$ To understand how multiple equilibria arise at low values of the elasticity of substitution consider the first equilibrium in the second panel of Figure 1. As the price of good 1 is high relative to the price of good $2, \bar{q}=0.47$, the value of the endowment of country 1 is high relative to country 2 . Agents in country 2 are willing to pay the high price for good 1 and country 1 ends up consuming most of the two goods. The same logic applies in the third equilibrium, $\bar{q}=2.12$, with the roles of country 1 and 2 being reversed. The second equilibrium is the symmetric equilibrium featuring $\bar{q}=1$. If the elasticity of substitution is high, equilibria 1 and 3 cannot exist.

The dynamic extension of the static economy with a low elasticity of substitution delivers a simple example of an economy with sunspot equilibria. Let preferences admit an expected utility representation. Agents receive a fixed endowment every period and there are no international financial markets. The dynamic economy is then simply the repeated static economy. A sunspot equilibrium is given by a system of the three spot prices and a probability distribution $\pi$ over the three spot prices: although the fundamentals of the economy, i.e., the endowments, are unaffected by the realization of the state, the equilibrium prices and allocations differ across states. $^{10}$

\section{General Model}

The model is quite standard in the international business cycle literature and it is closely related to the seminal work of Backus et al (1995). There are two countries $(i=1,2)$, each populated by an infinite number of households of measure one. Each

\footnotetext{
${ }^{9}$ For the chosen parametrization of the model it is easily shown that for $\varepsilon<0.425$ there are multiple equilibria and that the equilibrium is unique for $\varepsilon>0.425$. For $\varepsilon=0.425$, however, there is a continuum of equilibria as the slope of the excess demand function is zero at $\bar{q}=1$. See also Appendix A.

${ }^{10}$ See in particular Cass and Shell (1983). Chiappori and Guesnerie provide an excellent introduction to the topic.
} 
country produces one good and the home and foreign good are imperfect substitutes in the households' utility functions. The two goods are produced under perfect competition using capital and labor. Agents have access to a non-contingent bond that pays one unit of country 1's currency.

Time is discrete and each period the economy experiences one of finitely many events $s_{t} . s^{t}=\left(s_{0}, s_{1}, \ldots, s_{t}\right)$ denotes the history of events up through and including period $t$. The probability, as of period 0 , of any particular history $s^{t}$ is $\pi\left(s^{t}\right)$. The initial realization $s_{0}$ is given.

\subsection{Households}

Households in country $i$ maximize their expected discounted lifetime utility subject to their budget constraint. All variables are expressed in per household units

$$
\begin{aligned}
& \max _{\substack{c_{i}\left(s^{t}\right), l_{i}\left(s^{t}\right), c_{i 1}\left(s^{t}\right), c_{i 2}\left(s^{t}\right) \\
k_{i}\left(s^{t}\right), i_{i}\left(s^{t}\right), b_{i}\left(s^{t}\right)}}^{\infty} \sum_{t=0}^{\infty} \sum_{s^{t}} \beta^{t} \pi\left(s^{t}\right) U\left(c_{i}\left(s^{t}\right), l_{i}\left(s^{t}\right)\right) \\
& \text { s.t. } \\
& P_{i}\left(s^{t}\right)\left(c_{i}\left(s^{t}\right)+i_{i}\left(s^{t}\right)\right) \leq \bar{P}_{i}\left(s^{t}\right) w_{i}\left(s^{t}\right) l_{i}\left(s^{t}\right)+\bar{P}_{i}\left(s^{t}\right) r_{i}\left(s^{t}\right) k_{i}\left(s^{t-1}\right) \\
& +\bar{P}_{i}\left(s^{t}\right) p_{i}\left(s^{t}\right)+b_{i}\left(s^{t-1}\right)-Q_{i}\left(s^{t}\right) b_{i}\left(s^{t}\right) \\
& k_{i}\left(s^{t}\right) \leq(1-\delta) k_{i}\left(s^{t-1}\right)+i_{i}\left(s^{t}\right)
\end{aligned}
$$

where $c_{i}, i_{i}, l_{i}$ and $k_{i}$ denote consumption, investment, labor, and capital, respectively. $P_{i}$ is the price of the final consumption-investment good, $\bar{P}_{i}$ is the price of good $i, \bar{P}_{i} r_{i}$ and $\bar{P}_{i} w_{i}$ are the nominal rental rate of capital and the nominal wage, $\bar{P}_{i} p_{i}$ denotes nominal profits, and $b_{i}$ denotes holdings of a non-contingent bond. $Q_{i}$ is the price of the bond. To rule out Ponzi-schemes, I assume that agents face an upper bound for borrowing $\bar{b}_{i}$ that is large enough to never bind in this application. 


\subsection{Firms}

Firms utilize labor and capital in order to produce the traded good under perfect competition. The technology is assumed to be of the constant elasticity of substitution type. Since capital is owned by households and rented out to firms, the solution to the firms' maximization problem can be found from

$$
\begin{aligned}
& \max _{l_{i}, k_{i}} F\left(l_{i}\left(s^{t}\right), k_{i}\left(s^{t-1}\right)\right)-w_{i}\left(s^{t}\right) l_{i}\left(s^{t}\right)-r_{i}\left(s^{t}\right) k_{i}\left(s^{t-1}\right) \\
& \text { s.t. } \\
& F_{i}\left(l_{i}, k_{i}\right)=\left[\omega_{l i}^{1-\kappa}\left(A_{i}\left(s^{t}\right) l_{i}\left(s^{t}\right)\right)^{\kappa}+\omega_{k i}^{1-\kappa} k_{i}\left(s^{t-1}\right)^{\kappa}\right]^{\frac{1}{\kappa}}, \\
& \text { if } \kappa<1 \text { and } \\
& F_{i}\left(l_{i}, k_{i}\right)=\left(\frac{A_{i}\left(s^{t}\right) l_{i}\left(s^{t}\right)}{\omega_{l i}}\right)^{\omega_{l i}}\left(\frac{k_{i}\left(s^{t-1}\right)}{\omega_{k i}}\right)^{\omega_{k i}}, \\
& \text { if } \kappa=0 .
\end{aligned}
$$

\subsection{International trade}

Households in country $i$ demand a consumption-investment good $\tilde{c}_{i}\left(=c_{i}+i_{i}\right)$. $\tilde{c}_{i}$ is an aggregate of the domestically produced good and the imports of the foreign good according to

$$
\tilde{c}_{i}\left(s^{t}\right)=c_{i}\left(s^{t}\right)+i_{i}\left(s^{t}\right)=\left[\alpha_{i 1}^{1-\rho} c_{i 1}\left(s^{t}\right)^{\rho}+\alpha_{i 2}^{1-\rho} c_{i 2}\left(s^{t}\right)^{\rho}\right]^{\frac{1}{\rho}},
$$

with $0<\alpha_{i j}<1$. The parameters $\alpha_{i j}$ will be calibrated to match aggregate trade shares in the data. ${ }^{11} \rho<1$ and $\varepsilon=\frac{1}{1-\rho}$ measures the elasticity of substitution between traded goods.

A household's optimal choices for consumption of the home and the foreign good

\footnotetext{
${ }^{11}$ This modelling strategy leads to (indentical) home-bias in consumption and investment $\left(\alpha_{i i} \geq \alpha_{i j}, i \neq j\right)$. An alternative yet equivalent strategy in this model is to introduce trading costs of the iceberg type.
} 
are determined from the cost minimization problem

$$
\begin{aligned}
& \min _{c_{i 1}\left(s^{t}\right), c_{i 2}\left(s^{t}\right)} \bar{P}_{1}\left(s^{t}\right) c_{i 1}\left(s^{t}\right)+\bar{P}_{2}\left(s^{t}\right) c_{i 2}\left(s^{t}\right) \\
& \text { s.t. } \\
& \tilde{c}_{i}\left(s^{t}\right)=\left[\alpha_{i 1}^{1-\rho} c_{i 1}\left(s^{t}\right)^{\rho}+\alpha_{i 2}^{1-\rho} c_{i 2}\left(s^{t}\right)^{\rho}\right]^{\frac{1}{\rho}} .
\end{aligned}
$$

The first order conditions for country $i$ 's households imply

$$
\frac{c_{i 1}\left(s^{t}\right)}{c_{i 2}\left(s^{t}\right)}=\frac{\alpha_{i 1}}{\alpha_{i 2}}\left(\frac{1}{\bar{q}\left(s^{t}\right)}\right)^{\frac{1}{\rho-1}}
$$

where I have defined the relative price to be

$$
\bar{q}\left(s^{t}\right)=\frac{\bar{P}_{2}\left(s^{t}\right)}{\bar{P}_{1}\left(s^{t}\right)} .
$$

This relative price relates to the real exchange rate as follows

$$
q\left(s^{t}\right)=\frac{P_{2}\left(s^{t}\right)}{P_{1}\left(s^{t}\right)}=\frac{\tau_{22}}{\tau_{11}}\left[\frac{\alpha_{11}+\alpha_{12}\left(\frac{\tau_{11}}{\tau_{12}}\left(s^{t}\right)\right)^{\frac{\rho}{1-\rho}}}{\alpha_{21}\left(\frac{\tau_{21}}{\tau_{22}}\right)^{\frac{\rho}{\rho-1}}+\alpha_{22}\left(\bar{q}\left(s^{t}\right)\right)^{\frac{\rho}{\rho-1}}}\right]^{\frac{1-\rho}{\rho}} .
$$

In what follows $P_{1}\left(s^{t}\right)$ is normalized to unity. Using goods market clearing, budget constraints, and optimality conditions the demand for good 2 in countries 1 and 2 can be expressed as

$$
\begin{aligned}
& c_{12}\left(s^{t}\right)=\frac{\alpha_{12} \bar{q}\left(s^{t}\right)^{\frac{1}{\rho-1}}}{\alpha_{11}+\alpha_{12} \bar{q}\left(s^{t}\right)^{\frac{\rho}{\rho-1}}}\left[y_{1}\left(s^{t}\right)+\frac{b_{1}\left(s^{t-1}\right)-Q_{1}\left(s^{t}\right) b_{1}\left(s^{t}\right)}{\Phi_{1}\left(s^{t}\right)}\right], \\
& c_{22}\left(s^{t}\right)=\frac{\alpha_{22}}{\alpha_{21}\left(\frac{1}{\bar{q}\left(s^{t}\right)}\right)^{\frac{\rho}{\rho-1}}+\alpha_{22}}\left[y_{2}\left(s^{t}\right)+\frac{b_{2}\left(s^{t-1}\right)-Q_{2}\left(s^{t}\right) b_{2}\left(s^{t}\right)}{\Phi_{1}\left(s^{t}\right) \bar{q}\left(s^{t}\right)}\right],
\end{aligned}
$$

and $\Phi_{1}\left(s^{t}\right)=\frac{\bar{P}_{1}\left(s^{t}\right)}{P_{1}\left(s^{t}\right)}$.

\subsection{Definition of Equilibrium}

A competitive equilibrium in the dynamic model is defined as follows: 
Definition 2 A competitive equilibrium is a collection of allocations $c_{i 1}\left(s^{t}\right), c_{i 2}\left(s^{t}\right)$, $c_{i}\left(s^{t}\right), i_{i}\left(s^{t}\right), y_{i}\left(s^{t}\right), k_{i}\left(s^{t}\right), l_{i}\left(s^{t}\right)$, prices $q\left(s^{t}\right), \bar{q}\left(s^{t}\right), w\left(s^{t}\right), r\left(s^{t}\right), Q_{i}\left(s^{t}\right)$, and profits $p_{i}\left(s^{t}\right), i=1,2$, such that $(i)$ for every household the allocations solve the household's maximization problem for given prices, (ii) for every firm profits are maximized, and (iii) the markets for labor, capital, goods, and bonds $\left(b_{1}\left(s^{t}\right)+\right.$ $\left.b_{2}\left(s^{t}\right)=0\right)$ clear.

\section{Computation and Calibration}

In a static model, the computation of the possibly multiple equilibria can be separated from the consideration of sunspot equilibria. However, in a dynamic model this is no longer possible. Each equilibrium path depends on the probability distribution over all the possible equilibria. To impose more discipline on the analysis, the following assumptions are made in the subsequent computations.

\subsection{More Assumptions}

As argued in Section 2, equilibrium multiplicity occurs because changes in the relative price lead to a shift in purchasing power that can be supported as equilibrium if the trade elasticity is low. In a dynamic economy with capital, labor, and internationally traded bonds the same intuition applies provided that markets are not complete. ${ }^{12}$

In order to characterize the equilibrium multiplicity in the general model, I impose two assumptions:

1. At time 1 country 2 experiences an unexpected rise in its technology. The shock follows an $A R(1)$ process with known persistence. Once the shock is realized agents perfectly foresee the future path of technology.

\footnotetext{
${ }^{12}$ In this model financial markets are complete only if they also provide insurance against the possible equilibrium multiplicity that I am about to discuss. See also Section 6.
} 
2. The agents' problem is modified to yield stationarity of the net foreign asset position under the first assumption. Two alternatives are considered:

(a) Agents face a convex cost for holding/issuing bonds as in Heathcote and Perri (2002), and Schmitt-Grohé and Uribe (2003). The collected fees are reimbursed to the agents by a lump-sum transfer. $\Gamma\left(\frac{B_{i}\left(s^{t}\right)}{\bar{P}_{i}\left(s^{t}\right)}\right)$ denotes the portfolio costs in terms of country $i$ 's traded good, where $\Gamma(0)=0$, $\Gamma^{\prime}(0)=0$, and $\Gamma^{\prime}>0$ otherwise. The budget constraint of a household is now given by

$$
\begin{aligned}
& P_{i}\left(s^{t}\right)\left(c_{i}\left(s^{t}\right)+i_{i}\left(s^{t}\right)\right) \leq \bar{P}_{i}\left(s^{t}\right) w_{i}\left(s^{t}\right) l_{i}\left(s^{t}\right) \\
& +\bar{P}_{i}\left(s^{t}\right) r_{i}\left(s^{t}\right) k_{i}\left(s^{t-1}\right)+\bar{P}_{i}\left(s^{t}\right) p_{i}\left(s^{t}\right) \\
& +b_{i}\left(s^{t-1}\right)-Q_{i}\left(s^{t}\right) b_{i}\left(s^{t}\right)-\bar{P}_{i}\left(s^{t}\right) \Gamma\left(\frac{B_{i}\left(s^{t}\right)}{\bar{P}_{i}\left(s^{t}\right)}\right)+T_{i}\left(s^{t}\right) .
\end{aligned}
$$

(b) Agents' intertemporal discount factors are endogenous as in Uzawa (1968). ${ }^{13}$ More specifically, the problem of the representative household is given by

$$
\begin{aligned}
& \max _{\substack{c_{i}\left(s^{t}\right), l_{i}\left(s^{t}\right) c_{i 1}\left(s^{t}\right), c_{i 2}\left(s^{t}\right) \\
k_{i}\left(s^{t}\right), i_{i}\left(s^{t}\right), b_{i}\left(s^{t}\right)}} \sum_{t=0}^{\infty} \sum_{s^{t}} \theta_{i}\left(s^{t}\right) \pi\left(s^{t}\right) U\left(c_{i}\left(s^{t}\right), l_{i}\left(s^{t}\right)\right) \\
& \text { s.t. } \\
& \theta_{i}\left(s^{t+1}\right)=\beta_{i}\left[U\left(c_{i}\left(s^{t}\right), l_{i}\left(s^{t}\right)\right)\right] \theta_{i}\left(s^{t}\right)
\end{aligned}
$$

and equations (7) and (8).

The first assumption eliminates all uncertainty including sunspots from period 2 onwards. This assumption allows the characterization of the equilibrium multiplicity without the additional complications that arise in a fully stochastic model with incomplete markets, borrowing constraints and endogenous capital accumulation. Identifying multiple equilibria is a tedious task, but without this assumption, one does not even know where to look for the equilibrium multiplicity.

\footnotetext{
${ }^{13}$ See Mendoza (1991), Corsetti et al (2008), and Schmitt-Grohe and Uribe (2003) for applications of this concept. Preferences with intertemporal dependences were introduced by Uzawa (1968) and the concept has been extended and clarified by Epstein $(1983,1987)$.
} 
The second assumption is a direct consequence of the first. Since I assume perfect foresight from period 2 onwards, the long-run equilibrium value of the net foreign asset position changes in response to the temporary shock. ${ }^{14}$ Unfortunately, this long-run value and therefore the long-run equilibrium are unknown thereby making the computational procedure suggested below inapplicable. Under the second assumption, however, net foreign assets are known to return to their pre-shock level. ${ }^{15}$

\subsection{Solution Method}

I describe the solution algorithm for finding the equilibrium path of the endogenous variables for the (perfect-foresight) experiment described above.

The major step in accounting for equilibrium multiplicity is to generate a good starting guess. Unfortunately, local approximation methods such as linearization or second-order perturbation methods are of little help. These methods can only find one equilibrium. While the suggested algorithm does not guarantee the detection of all equilibria, it does detect some. ${ }^{16}$

To find the equilibrium paths I use a combination of forward and backward shooting algorithms. Since shooting algorithms with many state variable are computationally intensive, the algorithm starts under the assumption of fixed capital. Endogenous capital accumulation is then reintroduced once a starting guess is found. Without loss in generality, the stationarity inducing devices introduced under assumption 2 are parameterized to induce zero net-foreign asset positions in any steady

\footnotetext{
${ }^{14}$ This problem is similar to the non-stationarity problem in linearized models with incomplete markets. Endogenous discounting and convex portfolio costs are only two possibilities to address the non-stationarity problem. See Schmitt-Grohé and Uribe (2003), Kim and Kose (2003), and Boileau and Normandin (2005) to obtain a complete overview about this topic. An interesting approach using a perpetual youth model is due to Ghironi (2003).

${ }^{15}$ If solving a fully stochastic version of the model, the second assumption can be omitted. In ongoing research I analyze equilibrium multiplicity in an endowment economy with borrowing constraints and sunspot shocks.

${ }^{16} \mathrm{As}$ in static general equilibrium theory, little is known about the number of equilibria in a model unless uniqueness is proven.
} 
state.

\section{Algorithm 1}

1. Choose the parametrization of the model, set $\omega_{k i} \approx 0$, and assume that capital is fixed at its steady level, i.e., remove the Euler equation for capital from the model. Assume that there are no shocks.

2. For each locally stable steady state compute the stable manifold using a reverse shooting algorithm as described in Judd (1998). I reduce the dimension of the problem to the relative price $\bar{q}$, and bond holdings $b_{1}$. The resulting manifold shows the path along which the economy converges to a steady state from the initial net foreign asset position $b_{1}\left(s_{-1}\right)$ and the initial value of the relative price $\bar{q}\left(s_{0}\right)$.

3. Compute the equilibrium path of the endogenous variables to a purely transitory shock in time $1, A_{2}\left(s_{1}\right)$. Prior to the shock the economy is assumed to be in steady state. Since bond holdings can freely adjust from one period to the other, the economy must move along the stable manifold(s) computed under step 2 starting from the second period on. To find a candidate equilibrium path:

(a) choose a pair $\left(b_{1}\left(s^{1}\right), \bar{q}\left(s^{2}\right)\right)$ on the manifold as a guess for the position of the economy in the second period, the period right after the shock,

(b) use the first order conditions of the model to compute the implied value of $b_{1}\left(s_{0}\right)$ if $A_{2}\left(s_{1}\right)>0$. Since bond holdings are 0 in the steady state, a bond-price pair $\left(b_{1}\left(s^{1}\right), \bar{q}\left(s^{2}\right)\right)$ is an equilibrium only if the implied bond holdings for state $s_{0}$ satisfy $b_{1}\left(s_{0}\right)=0$.

4. This candidate impulse response is used as starting guess in a code that solves non-linear perfect foresight problems using a Newton method. The solution algorithm for this step borrows heavily from the DYNARE code "simul" and is implemented in FORTRAN. 
5. Once an equilibrium path has been computed, I reintroduce the dynamic investment decision and increase $\omega_{k i}$ to its desired value. At this stage it is also convenient to increase the persistence of the shock if desired.

Figure 2 shows the stable manifolds computed under step 2 for the case of convex portfolio costs (top panel) and endogenous discounting (lower panel) with $\varepsilon \approx 0.44$ and $\omega_{k i}=0.01$. In the case of convex portfolio costs the two stable steady states which are marked by the filled in circles feature different capital stocks and therefore the two manifolds do not "connect". As argued in Bodenstein (2007), the third steady state with $\bar{q}=1$ is unstable. In the case of endogenous discounting the steady state is always unique and stable as indicated by the black arrows.

\subsection{Calibration}

Most parameter choices are taken straight from the international business cycle literature and are summarized in Table 1. The utility function is assumed to be additive separable between labor and consumption

$$
U(c, l)=\frac{c^{1-\sigma}}{1-\sigma}-\chi_{0} \frac{l^{1+\chi}}{1+\chi} .
$$

Following assumption $2 a$ the convex portfolio costs are chosen to be quadratic

$$
\Gamma\left(\frac{B_{i}}{\bar{P}_{i}}\right)=\frac{1}{2} \phi_{b}\left(\frac{B_{i}}{\bar{P}_{i}}\right)^{2},
$$

and under assumption $2 b$ the endogenous discount factor is given by

$$
\beta\left(c_{i}, l_{i}\right)=\left[1+\exp \left(\frac{c^{1-\sigma}}{1-\sigma}-\chi_{0} \frac{l^{1+\chi}}{1+\chi}\right)\right]^{-\psi_{i}} .
$$

The $\psi_{i}$ 's are chosen such that $\beta\left(c_{i}, l_{i}\right)$ takes on the value of $\beta$ at the steady state. The parameters $\alpha_{11}$ and $\alpha_{12}$ determine the home bias in consumption. Following the applied DSGE literature, these consumption weights are chosen to match the import to GDP ratio for the U.S., which is about $13 \% .^{17}$

\footnotetext{
${ }^{17}$ Absent home bias in consumption the equilibrium is always unique in the symmetric economy.
} 


\section{$5 \quad$ Results}

Before discussing the results for the dynamic economy a look at the steady state equilibria for this economy seems instructive. Similar to the endowment economy in Section 2, there are three steady states absent international financial markets provided that the elasticity of substitution between the traded goods $\varepsilon$ is sufficiently low. For the above calibration this is true for $\rho=-1.6{ }^{18}$ The same steady states arise with incomplete markets under the additional restriction that steady state bond holdings are zero.

For an elasticity of substitution $\varepsilon \approx 0.38(\rho=-1.65)$ the three different values of the relative price that are consistent with an equilibrium are given in the first column of Table 2. Furthermore, Table 2 summarizes how capital, employment and output in country 1 differ across steady states. The value of variable $x_{2}\left(\bar{q}^{*}\right)$ for country 2 coincides with $x_{1}\left(\frac{1}{\bar{q}^{*}}\right)$. In contrast to the endowment economy, the differences in purchasing power across equilibria also have an impact on the supply side of the economy. For example, if the relative price is in favor of country 1, i.e., $\bar{q}=0.35$, country 1 accumulates higher capital, enjoys higher output and uses less labor in the production process.

\subsection{Convex Portfolio Costs}

Under the above specification of the portfolio cost function the steady state value of bond holdings is uniquely determined to be zero. Thus, the steady states of the model with portfolio costs are the same as in the economy without international financial markets.

Similar to Bodenstein (2007), the steady state with $\bar{q}=1$ is dynamically unstable, while the remaining two are stable. Prior to the realization of the positive

\footnotetext{
${ }^{18}$ In Appendix A, I provide more details on the derivation of this threshold value. See also the discussion in Section 5.2.2.
} 
technology shock in the foreign country, the economy is assumed to be in the steady state with $\bar{q}=0.35$. The size of the shock is set equal to $0.01 \%$.

\subsubsection{Impulse Response Functions}

Figure 3 plots the impulse response functions for selected variables in percentage deviations from the original steady state. Paths 1 (solid line) and 2 (dashed line) lead back to the original steady state, whereas path 3 (dotted line) converges to the other stable steady state with $\bar{q}=2.86$. As the magnitude of the responses is considerably smaller for path 1 than for the other two paths, Figure 4 plots the responses of the variables for the non-linear solution of path 1 (solid line).

The reasoning behind the equilibrium multiplicity in the dynamic economy is the same as in the static endowment economy: given the predetermined capital stock, there are three locally isolated price equilibria each associated with a different distribution of relative purchasing power. If the capital stock adjusted quickly, one would expect that there is one path in the neighborhood of each of the three steady states. However, the capital stock is predetermined relative to the shock and adjusts slowly afterwards. Hence, only path 1 starts in the neighborhood of a steady state the original steady state in the case of path 1 . In particular, path 3 , which converges to the steady state with $\bar{q}=2.86$, starts with allocations and prices that are far away from their long run values. This fact is driven by the differences in the capital stock in the original steady state $(\bar{q}=0.35)$ and the new one $(\bar{q}=2.86)$ as reported in Table 2.

Path 1 is the sole path that linearization around the original steady state detects. In response to the transitory technology shock output rises in the foreign country for a few periods. Simultaneously, the real exchange rate appreciates for the home country reflecting a change of the relative price $\bar{q}$ against the foreign country. Even more purchasing power is shifted to the home country and the home country's consumption rises relative to the foreign country's. 
While the dynamics for path 1 are solely driven by the increase in foreign technology, the dynamics for paths 2 and 3 are driven mostly by the large shifts in relative purchasing power towards the foreign country that are associated with the rise in the relative price of the foreign good. The effects of the technology shock are negligible in these two cases. In fact, the same responses would be obtained if the technology shock was replaced by a pure sunspot shock. Demand in the home country (consumption plus investment) falls considerably. Home output falls as well, but by less than home consumption, as the foreign country raises its demand for the home good due to generally stronger foreign demand. Furthermore, the trade balance to GDP ratio falls on impact, indicating that the home country borrows funds to smooth the consequences of the shock.

\subsubsection{Local Approximation}

As shown in Figure 4, path 1 can be reliably approximated using (log-)linearization techniques around the model's non-stochastic steady state. However, this is not the case for paths 2 and 3 .

Consider path 3 first. In general, one should be able to compute an approximate path using local approximation techniques around the new steady state with $\bar{q}=$ 2.86. The values of the predetermined variables (capital stocks and bonds) in the original steady state are then taken as starting values of the system. While this approach works reasonably well if the share of capital in production is low, Figure 5 shows that this is not true for the chosen calibration. The linear approximation to path 3 (solid line) and the actual path 3 (dotted line) differ considerably. These differences are most obvious in the exaggerated response of the real exchange rate and the relative price $\bar{q}$ in the linearized framework. A second order perturbation approach yields results that are even further away from the true path. Equally disappointing results are obtained with a starting guess that uses knowledge about the actual path 3, namely the values that the state variables assume for the period 
right after the shock. These observations suggest, that for a realistic calibration of the model the deviations of the starting values from their new steady state values are simply too large for path 3 to be correctly approximated by local approximation methods.

In the case of path 2 the attempt of using local approximation techniques is even less successful. Prior to computing path 2 it is not even known whether path 2 converges back to the original steady state or to the other stable steady state. Depending on the magnitude of the technology shock and the share of capital in production $\omega_{k i}$, one can find either behavior. Even if the convergence properties of path 2 are known, one faces the question how to approximate this path by a first- or second-order approximation technique that expands the equilibrium system around the steady state to which the system will converge. For a given realization of the state variables (technology, home and foreign capital, international bond holdings) these methods prescribe a unique adjustment path. As the economy is in steady state prior to the shock, the adjustment path that is recovered using perturbation methods is path 1 . Using the values of the state variables of the first period after the shock along the true path 2 rather than those of the period of the shock as starting values in the approximated decision rules does not recover path 2 either.

\subsection{Endogenous Discount Factor}

As discussed in more detail in Bodenstein (2007), there is always a unique steady state irrespective of the value of the trade elasticity if the agents' discount factors are endogenous. In the following I calibrate the free parameters in the functional form of the endogenous discount factor such that the unique stable steady state features $\bar{q}=$ 1. Obviously, this uniqueness is somewhat artificial, since the underlying economy without endogenous discounting still has multiple steady states with zero bond holdings if $\rho<-1.60$ for the above calibration.

However, the analysis with an endogenous discount factor provides insights that 
go beyond those gained in the model with convex portfolio costs. First, the version of the model allows for the construction of equilibria around the symmetric steady state as in Corsetti et al (2008) and Thoenissen (2008). Second, it turns out that there can be multiple equilibria even if $\rho>-1.60$, i.e., for calibrations that never admit multiple steady states.

\subsubsection{Impulse Response Functions}

Figure 6 plots the impulse response functions for selected endogenous variables for $\rho \approx-1.469$ to a purely transitory shock to the foreign country's technology level of $0.01 \%$. Similar to the analysis under convex portfolio costs, the technology shock is the major determinant of the equilibrium dynamics for only one of the three paths. The other two paths are associated with large shifts in relative purchasing power and the effects of the technology shock are negligible. However, all these paths lead the economy back to the original steady state with $\bar{q}=1$.

Path 1 (solid line) implies a persistent decline of the relative price $\bar{q}$ that increases the purchasing power of the home country. Consequently, home consumption, investment, and output show a strong rise. The foreign country is willing to trade at the low relative price in order to receive at least some of the home good from which it can hardly substitute away. The roles are reversed for path 3 (dotted line) which features a strong rise in the relative price.

Path 2 (dashed line) has received considerable attention in the recent literature, see, e.g., the work of Corsetti et al (2008) and Thoenissen (2008). Subject to some caveats discussed below, this is the unique path that is recovered by linearization around the model's steady state. ${ }^{19}$ The increase in foreign technology raises foreign output. In contrast to the dynamics under a high elasticity of substitution the

\footnotetext{
${ }^{19}$ In fact, Crosetti et al (2008) do not consider the case of multiple equilibria as they restrict attention to the solution obtained by log-linearizing the model around its symmetric deterministic steady state. See also footnote 7 of their work.
} 
price of the foreign good does not need to fall under a low elasticity of substitution: if $\bar{q}$ rises, the value of the foreign country's production increases, while it falls in the home country. In both countries there is a tendency to substitute away from the more expensive foreign good. This situation can only be an equilibrium if the increase in purchasing power in the foreign country offsets the negative impact that the higher price and lower home income exert on overall demand for the foreign good.

Corsetti et al (2008) refer to the appreciation of the terms of trade in light of a positive supply shock as "negative transmission mechanism". ${ }^{20}$ From an applied point of view, path 2 has certain appealing features. In a richer model with distribution costs and nontraded goods, Corsetti et al (2008) invoke this mechanism to address two important puzzles in the international macroeconomics literature, namely the Backus-Smith puzzle (Backus and Smith (1993)) and the real exchange rate volatility puzzle. If the implied elasticity of substitution between foreign and domestic goods is low enough, an appreciation of the relative price and the real exchange rate for the home country goes along with an increase in the home country's consumption relative to the foreign country's. In addition, the real exchange rate is about as volatile as in the data. Furthermore, just as the model presented in Thoenissen (2008) and in line with the data their model predicts a negative crosscountry correlation for consumption and a negative correlation of output with the real exchange rate - a major step forward relative to previous attempts in the literature. The model presented here can replicate all of these findings if $\rho$ is sufficiently close to but less than a critical value of -1.4685 . The next section sheds more light on this critical value of the trade elasticity of substitution.

\footnotetext{
${ }^{20}$ In particular, see the exposition in Section 3 of Corsetti et al (2008). In most of their analysis the authors focus on the case of a low trade elasticity of substitution. However, they also identify a case of negative transmission for a high trade elasticity of substitution that is unrelated to the analysis presented in this paper.
} 


\subsubsection{Multiple Equilibria and the Short-Run Excess Demand Function}

In Section 5.1 the analysis of the multiple equilibrium paths relies on the presence of multiple steady state equilibria, i.e., $\rho<-1.60$. However, as just shown equilibrium multiplicity can also occurs if there is a unique steady state with $\rho>-1.60$. The reason for this finding lies in the behavior of the economy in the short-run: the capital stock is not fully flexible. Consequently, if the relative price moves against country $i$ its agents' ability to lower the production of good $i$ and offset some of the adverse movements in the relative price is diminished. Hence, multiple equilibria can exist in the short run but may be absent in the long run.

More formally, the short-run excess demand function can be upward-sloping while the long-run excess demand function is downward-sloping. Figure 7 plots the slope of the excess demand function around $\bar{q}=1$, i.e., the partial derivative of the excess demand for good 2 with respect to the relative price, denoted by $\frac{\partial z_{2 t}}{\partial \bar{q}_{t}}$, for the two horizons as a function of $\rho$. The underlying derivations are provided in Appendix A. The scale for the short-run and the long-run slopes are depicted on the left and the right vertical axis, respectively. A positive value of the slope indicates the presence of multiple equilibria. The curve labeled "long run excess demand" intersects the horizontal axis at $\rho=-1.60$, whereas the curve labeled "short run excess demand" intersects with the horizontal axis for the higher value of $\rho=-1.4685$.

The change in the sign of the slope of the excess demand function, sign $\left(\frac{\partial z_{2 t}}{\partial \bar{q}_{t}}\right)$, can be easily detected by looking at the policy function for the relative price $\bar{q}$ that is obtained from linearization around the steady state with $\bar{q}=1$. If $\operatorname{sign}\left(\frac{\partial z_{2 t}}{\partial \bar{q}_{t}}\right)$ changes sign so do the coefficients on the endogenous state variables in the policy function for the relative price.

To offer an economic interpretation, consider the coefficient on current bond holdings which is denoted by $\frac{\partial \bar{q}_{t}}{\partial b_{1 t-1}}$. This coefficient is positive if $\operatorname{sign}\left(\frac{\partial z_{2 t}}{\partial \bar{q}_{t}}\right)$ is positive and negative otherwise. Suppose $b_{1 t-1}>0$, i.e., the home country lends 
funds to the foreign country in period $t-1$. In order to pay back its debt obligations in time $t$, the foreign country has to increase its total export revenue which implies that the price and/or the number of exported units have to rise. If $\frac{\partial \bar{q}_{t}}{\partial b_{1 t-1}}<0$, the foreign country increases the number of units determined for exports and the relative price of the foreign good falls. Since the elasticity of substitution is high, a small decline in the price leads to a relatively large increase in exports and the total export revenue rises. If $\frac{\partial \bar{q}_{t}}{\partial b_{1 t-1}}>0$, the relative price of the foreign good increases and the number of exported units falls. However, since the substitutability between the traded goods is low, a large price increase leads to a relatively small decline in the number of exported units and the total export revenue rises. ${ }^{21}$

Remember, that the slope of the short-run excess demand function is close to zero in the neighborhood of $\rho=-1.4685$ for the equilibrium with $\bar{q}=1$. When deriving the linear approximation to the law of motion of the relative price one divides by a number that is arbitrarily close to zero. This finding explains why Thoenissen (2008), Corsetti et al (2008), de Walque et al (2005), and Benigno and Thoenissen (2008) find that in each of their models there is a critical value of the trade elasticity of substitution for which the volatility of the real exchange rate is infinite. Such behavior of the model is again indicative of equilibrium multiplicity. ${ }^{22}$

\footnotetext{
${ }^{21}$ The exact value for which $\frac{\partial \tilde{q}_{t}}{\partial b_{1 t-1}}$ switches sign depends on the second assumption in Section 4.1. With convex portfolio costs the sign switch occurs at $\rho=-1.53$. It can be shown that for $-1.65<\rho<-1.53$ there are at least three equilibrium paths each converging to the unique steady state with $\bar{q}=1$ in response to a technology shock. Obviously, this situation is somewhat of a knife-edge case, as the steady state with $\bar{q}=1$ becomes unstable for $\rho<-1.65$ and the uniqueness of the equilibrium for $\rho>-1.53$.

${ }^{22}$ Benigno and Thoenissen (2008) and de Walque et al (2005) do not assume that the agents' discount factors are endogenous to invoke stationarity of the net foreign assets. Benigno and Thoenissen (2008) assume convex portfolio costs, whereas de Walque et al (2005) do not invoke stationarity at all. Nevertheless, the finding about the slope of the short-run excess demand function and the volatility of the real exchange rate fully applies to their models.
} 


\subsubsection{Local Approximation}

The existence of multiple equilibria poses some challenges to applying the model with a low trade elasticity of substitution. For example, it turns out that for a sufficiently large technology shock only one of the three equilibrium paths exists. For $\rho \approx-1.469$ the maximum size of the technology shock in the foreign country for which all three paths exists is around $0.1 \%$. For shocks larger than $0.1 \%$, only path 1 exists. ${ }^{23}$

In particular, this finding poses a problem if relying on local approximation techniques. Log-linearization around the model's unique steady state delivers an approximation of path 2 as the sole equilibrium path. Figures 8 and 9 show the possible computational errors for a calibration of the technology shock that follows Backus et al (1995). The shock to the foreign country's technology is $0.85 \%$ with persistence of 0.95 . The solid line in Figure 8 shows the unique equilibrium path for this technology shock. The dashed line is the suggested solution path derived from log-linearization around the steady state. The discrepancy between the two paths is obviously large. To convince the reader of the (in-)accuracy of the two suggested solution paths Figure 9 plots the approximation errors in the three dynamic equations of the model: the two Euler equations for capital and the risk sharing condition. The systematic nature of the approximation error indicates, that the dashed line (path 2) is not a solution of the model for a technology shock of size $0.85 \%$.

The closer the value of the elasticity of substitution is to the threshold level of $\varepsilon$ (meaning $\rho$ close to -1.4685 ), the smaller is the size of the technology shock for which path 2 exists. For a calibration of $\rho=-1.65$ as in Section 5.1, all three impulse responses exist for a $0.85 \%$ technology shock.

\footnotetext{
${ }^{23}$ If the positive shock to technology occurs in the home country, only path 3 exists. Similar logic applies to negative technology shocks.
} 


\section{Sensitivity}

The results are sensitive to three types of changes: parameters, model specification and the assumptions about financial markets. If financial markets are complete with respect to all states of nature (fundamental and non-fundamental), the equilibrium is always unique. However, if agents cannot insure against self-fulfilling fluctuations, sunspot equilibria can be constructed and there will be multiple equilibria provided that the trade elasticity is sufficiently low. Therefore, multiple equilibria will also be present in models with a richer set of assets, unless the assets span the complete market. As noted earlier, fundamental shocks are not really needed in the analysis, but they facilitate the computations and allow for comparisons of my results to the literature.

\subsection{Sensitivity to Parametrization}

Changes in the underlying model parameters affect the threshold level of the trade elasticity $\bar{\varepsilon}$ for which the model displays multiple equilibria as follows:

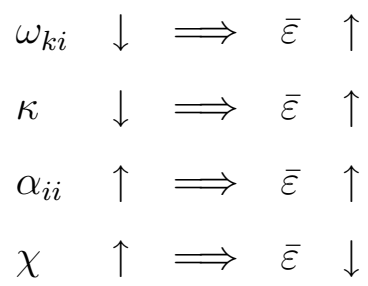

Both lowering the share of capital in production $\omega_{k i}$ or the elasticity of substitution between capital and labor $\kappa$ makes the economy look more like an endowment economy and raises the threshold level $\bar{\varepsilon}$ for which multiple equilibria are observed. Increasing home bias, i.e., a rise in $\alpha_{i i}$, also leads to a higher value of $\bar{\varepsilon}$ as shifts in relative purchasing power become less relevant with each country consuming mostly its own good.

The effect of lowering the labor supply elasticity (raising $\chi$ ) depends on the value of $\sigma$. If $\sigma>1$, the threshold level $\bar{\varepsilon}$ falls in response to a rise in $\chi$. However, if 
$\sigma<1$, a rise in $\chi$ lowers $\bar{\varepsilon}$. All these results can be obtained more formally from the derivations of the long- and short-run excess demand function that are provided in Appendix A.

\subsection{Sensitivity to Model Specification}

Multiple equilibria of the type discussed here can also occur in richer models with a low trade elasticity of substitution. A prominent example is the model with nontraded goods and distribution costs that is at the core of Corsetti et al (2008). In that model the implied elasticity of substitution between the home and foreign good at the consumer level is endogenous. Corsetti and Dedola (2005) mention the possibility of multiple steady states in such a model but do not analyze the dynamic case.

The following example serves to highlight some additional challenges that arise in models with distribution costs. Assume that agents in country $i$ are endowed with $y_{i}$ units of the traded good $i$ and $y_{i N}$ units of a nontraded good. Agents consume the two traded goods and their own nontraded good. However, in order to consume one unit of a traded good, agents have to forgive $\eta$ units of their nontraded good. In the static economy agent $i$ solves

$$
\begin{aligned}
& \max _{c_{i T}, c_{i N}, c_{i 1}, c_{i 2}} c_{i}=\left[\left(\alpha_{i T}\right)^{1-\phi} c_{i T}^{\phi}+\left(\alpha_{i N}\right)^{1-\phi} c_{i N}^{\phi}\right]^{\frac{1}{\phi}} \\
& \text { s.t. } \\
& P_{i N} c_{i N}+\left(\bar{P}_{1}+\eta P_{i N}\right) c_{i 1}+\left(\bar{P}_{2}+\eta P_{i N}\right) c_{i 2} \leq \bar{P}_{i} y_{i}+P_{i N} y_{i N},
\end{aligned}
$$

where $c_{i T}=\left[\left(\alpha_{i 1}\right)^{1-\rho} c_{i 1}^{\rho}+\left(\alpha_{i 2}\right)^{1-\rho} c_{i 2}^{\rho}\right]^{\frac{1}{\rho}}$. The market clearing conditions for this economy are

$$
\begin{aligned}
c_{11}+c_{21} & \leq y_{1} \\
c_{12}+c_{22} & \leq y_{2} \\
c_{i N}+\eta\left(c_{i 1}+c_{i 2}\right) & \leq y_{i N}
\end{aligned}
$$


with $i=1,2$. Following Corsetti et al (2008), let $\alpha_{i T}=0.55, \alpha_{i N}=0.45, \alpha_{11}=$ $\alpha_{22}=0.72, \alpha_{12}=\alpha_{21}=0.28, \eta=1.09, \rho=-0.17$, and $\phi=-0.35$. I set the ratio of nontraded to traded goods $\frac{y_{i N}}{y_{i}}$ equal to 2.25 , which is of similar magnitude as the ratio of service to manufacturing output in the U.S., the common proxies for traded and nontraded goods. For this parametrization, the trade elasticity of substitution between the foreign and the domestic good is around 0.27 , the producer price elasticity of traded goods is around 0.68 , and the consumer price elasticity of traded goods is $\frac{1}{1-\rho}=0.85$.

This endowment economy features a unique equilibrium with the relative price $\bar{q}=\frac{\bar{P}_{1}}{P_{2}}=1$. Consider, however, a 3 percent decline of the endowment with both traded goods while keeping the endowment with nontraded goods constant. Two new equilibria arise, one with $\bar{q}=0.82$ and the other one with $\bar{q}=1.22$. However, the equilibrium remains unique if the endowment with traded goods increases in both countries by the same amount. Hence, with an endogenous trade elasticity of substitution symmetric shocks can have very different implications for the number of equilibria and the resulting dynamics of the model.

\section{Conclusions}

Dynamic models with multiple equilibria can give rise to complex dynamics. As a first step, I characterize the dynamics of three equilibrium paths in a standard model of the international business cycle under the assumption that the elasticity of substitution between traded goods is low.

The empirical literature reports a wide range of trade elasticities at the aggregate level from 0 to 1.5. Recent macroeconomic research has pointed towards low trade elasticities: Corsetti, Dedola, and Leduc (2008), Thoenissen (2008) and others have shown that business cycle models with low trade elasticities may explain several puzzles in international macroeconomics, such as the Backus-Smith puzzle, 
the real exchange rate volatility puzzle, or the cross country correlation puzzles for consumption and output (see Thoenissen (2008) for a comprehensive list). In estimated DSGE models Rabanal and Tuesta (2005), Lubik and Schorfheide (2005), and de Walque, Smets, and Wouters (2005) show estimates for the trade elasticity that are very low and in some cases close to zero. At least in some of these cases the results hinge on values of the trade elasticity of substitution that imply the presence of multiple equilibria. However, no study has discussed the presence multiple equilibria in these DSGE models in depth, let alone the possible dynamics. ${ }^{24}$

Going forward the literature faces two major possibilities to address the aforementioned aspects of the data. Using the insights of this paper, one can proceed by building fully stochastic general equilibrium models with low trade elasticities that explicitly allow for sunspot equilibria. Such work requires the use of global approximation methods and is computationally intensive. It also seems important to continue the search for alternative models. Oil shocks as in Backus and Crucini (1998) and Bodenstein, Erceg, Guerrieri (2008), or investment-specific shocks as in Raffo (2008) are potentially promising. In the meantime trade adjustment costs as in Erceg, Guerrieri and Gust (2006) and taste shocks as in Corsetti et al (2008) can serve as simple fixes in the estimation of DSGE models to prevent the estimation algorithm from forcing the elasticity of substitution towards very low values in the attempt of fitting the model to the data.

\footnotetext{
${ }^{24}$ Corsetti and Dedola (2005) mention the possibility of multiple in such a framework. The working paper version of that paper provides some analysis of the steady state case.
} 


\section{References}

[1] Azariadis, C. (1981). Self-fulfillling Prophecies. Journal of Economic Theory $25,380-396$.

[2] Backus, D., and M. Crucini (1998). Oil Prices and the Terms of Trade. Journal of International Economics 50, 185-213.

[3] Backus, D., P. Kehoe, and F. Kydland (1995). International Business Cycles: Theory and Evidence. In T. Cooley (ed.) Frontiers of Business Cycle Research Princeton University Press, 331-356.

[4] Backus, D. and G. Smith (1993). Consumption and Real Exchange Rates in Dynamic Economies with Non-traded Goods. Journal of International Economics 35, 297-316.

[5] Benhabib, J. and R. Farmer (1994). Indeterminacy and Increasing Returns. Journal of Economic Theory 63, 19-46.

[6] Benigno, G. and C. Thoenissen (2008). Consumption and Real Exchange Rates with Incomplete Markets and Non-traded Goods. Journal of International Money and Finance, forthcoming.

[7] Bodenstein, M. (2007). Closing Large Open Economy Models. International Finance Discussion Papers 867, Board of Governors of the Federal Reserve System.

[8] Bodenstein, M., C. Erceg, and L. Guerrieri (2007). Oil Shocks and External Adjustment. International Finance Discussion Papers 897, Board of Governors of the Federal Reserve System.

[9] Boileau, M. and M. Normandin (2005). Closing International Real Business Cycle Models with Restricted Financial Markets. Center for Economic Analysis, University of Colorado at Boulder. 
[10] Broda, C. and D. Weinstein (2006). Globalization and the Gains from Variety. Quarterly Journal of Economics 121, 541-585.

[11] Cass, D. and K. Shell (1983). Do Sunspots Matter? Journal of Political Economy $91,193-227$.

[12] Chari, V.V., P. Kehoe, and E. McGrattan (2002). Can Sticky Prices Generate Volatile and Persistent Real Exchange Rates? Review of Economic Studies 69, 633-63.

[13] Chiappori, P. and R. Guesnerie (1991). Sunspot Equilibria in Sequential Market Models. In W. Hildenbrand and H. Sonnenschein (eds.) Handbook of Mathematical Economics, vol.4. Amsterdam: North Holland.

[14] Collard, F. and H. Dellas (2002). Technology Shocks and Employment. CEPR Discussion Papers 3680.

[15] Corsetti, G. and L. Dedola (2005). A Macroeconomic Model of International Price Discrimination. Journal of International Economics 67, 129-155.

[16] Corsetti, G., L. Dedola, and S. Leduc (2005). International Risk-sharing and the Transmission of Productivity Shocks. Review of Economic Studies 75, 443473.

[17] de Walque, G., F. Smets, and R. Wouters (2005). An Estimated Two Country DSGE Model for the Euro Area and the US Economy. Working Paper.

[18] Enders, Z. and G. Mueller (2008). On the International Transmission of Technology Shocks. EUI Working Paper ECO 2006/36.

[19] Epstein, L. (1983). Stationary Cardinal Utility and Optimal Growth under Uncertainty. Journal of Economic Theory 31, 133-152.

[20] Epstein, L. (1987). A Simple Dynamic General Equilibrium Model. Journal of Economic Theory 41, 68-95.

[21] Erceg C., C. Gust, and L. Guerrieri (2006). SIGMA: A New Open Economy Model for Policy Analysis. International Journal of Central Banking 2, 1-50. 
[22] Ghironi, F. (2003). Macroeconomic Interdependence under Incomplete Markets. Journal of International Economics 70, 428-450.

[23] Heathcote, J. and F. Perri (2002). Financial Autarchy and International Business Cycles. Journal of Monetary Economics 49, 601-627.

[24] Hooper, P., K. Johnson, and J. Marquez (2000). Trade Elasticities for the G-7 Countries. Princeton Studies in International Economics 87.

[25] Kehoe, T. (1980). An Index Theorem for General Equilibrium Models with Production. Econometrica 48, 1211-1232.

[26] Kehoe, T. (1991). Computation and Multiplicity of Equilibria. In W. Hildenbrand and H. Sonnenschein (eds.) Handbook of Mathematical Economics, vol.4. Amsterdam: North Holland.

[27] Kim, S. and M. Kose (2003). Dynamics of Open Economy Business Cycle Models: Role of the Discount Factor. Macroeconomic Dynamics 7, 263-290.

[28] Lubik, T. and Schorfheide F. (2005). A Bayesian Look at New Open Economy Macroeconomics. NBER Macroeconomics Annual 2005.

[29] Mas-Colell, A., M. Whinston and J. Green (1995). Microeconomic Analysis. Oxford University Press, Oxford, UK.

[30] Mendoza, E. (1991). Real Business Cycles in a Small Open Economy. American Economic Review 81, 797-818.

[31] Rabanal, P. and V. Tuesta (2005). Euro-Dollar Real Exchange Rate Dynamics in an Estimated Two-country Model: What is Important and What is Not. International Monetary Fund.

[32] Raffo, A. (2008). Technology Shocks: Novel Implications for International Business Cycles. Board of Governors of the Federal Reserve System.

[33] Schmitt-Grohé, S. and M. Uribe (2003). Closing Small Open Economy Models. Journal of International Economics 61, 163-185. 
[34] Taylor, J. (1993). Macroeconomic Policy in a World Economy: from Economic Design to Practical Operation. Norton, New York, NY.

[35] Thoenissen, C. (2008). Exchange Rate Dynamics, Asset Market Structure, and the Role of the Trade Elasticity. CDMA Working Paper Series 0803.

[36] Uzawa, H. (1968). Time Preference, the Consumption Function and Optimum Asset Holdings. In J. Wolfe (ed), Value, capital and growth: papers in honor of Sir John Hicks. The University of Edinburgh Press, Edinburgh, 485-504.

[37] Whalley, J. (1985). Trade Liberalization among Major World Trading Areas. MIT Press, Cambridge, MA. 
Table 1: Calibration of Baseline Model

\begin{tabular}{|c|c|c|c|}
\hline Parameter & Used to Determine & Parameter & Used to Determine \\
\hline \multicolumn{4}{|c|}{ Parameters governing households' behavior } \\
\hline$\beta=0.99$ & discount factor & $\chi=5$ & labor supply elasticity ${ }^{a}$ \\
\hline$\sigma=1$ & intertemporal consumption elasticity & $\rho=-1.65$ & elasticity between traded goods \\
\hline$\alpha_{11}=0.87$ & weight on good 1 country 1's cons. basket & $\alpha_{12}=0.13$ & weight on good 2 country 1's cons. basket \\
\hline$\alpha_{21}=0.13$ & weight on good 1 country 2's cons. basket & $\alpha_{22}=0.87$ & weight on good 2 country 2's cons. basket \\
\hline \multicolumn{4}{|c|}{ Parameters governing firms' behavior } \\
\hline$\omega_{k}=0.33$ & share of capital in production & $\omega_{l}=0.67$ & share of capital in production \\
\hline$\delta=0.025$ & depreciation rate of capital & & \\
\hline \multicolumn{4}{|c|}{ Parameters governing asset dynamics } \\
\hline$\psi_{1}=0.0275$ & endogenous discounting & $\psi_{2}=0.0275$ & endogenous discounting \\
\hline$\phi_{b}=0.0025$ & adjustment costs & & \\
\hline
\end{tabular}

${ }^{a}$ The Frisch elasticity is $1 / \chi=0.2$.

Table 2: Steady State Values of Selected Prices and Allocations

\begin{tabular}{|c|c|c|c|}
\hline $\begin{array}{c}\text { Relative Price } \\
\bar{q}^{*}\end{array}$ & $\begin{array}{c}\text { Domestic Output } \\
y_{1}^{*}\end{array}$ & $\begin{array}{c}\text { Domestic Capital } \\
k_{1}^{*}\end{array}$ & $\begin{array}{c}\text { Domestic Labor } \\
l_{1}^{*}\end{array}$ \\
\hline 0.35 & 1.87 & 19.5 & 0.22 \\
1.00 & 1.81 & 17.0 & 0.23 \\
2.86 & 1.72 & 13.5 & 0.24 \\
\hline
\end{tabular}

Steady state values for country 2 are mirroring the values for country 1 . The value for variable $x_{2}$, at the equilibrium with $\bar{q}^{*}$ coincides with the equilibrium value for variable $x_{1}$ at the equilibrium $\frac{1}{\bar{q}^{*}}$. 
Figure 1: Excess Demand Function in the Endowment Economy
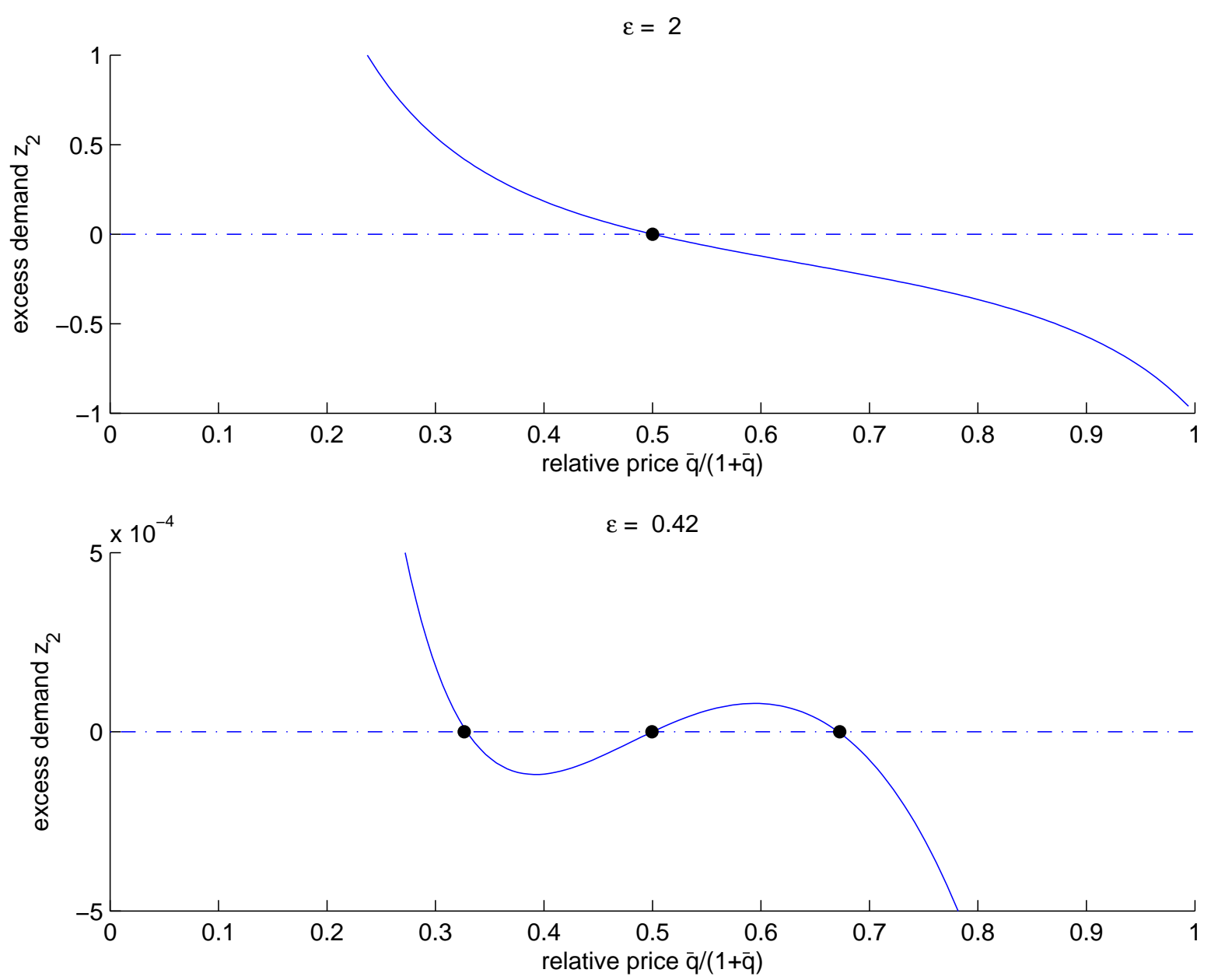
Figure 2: Stable Manifolds
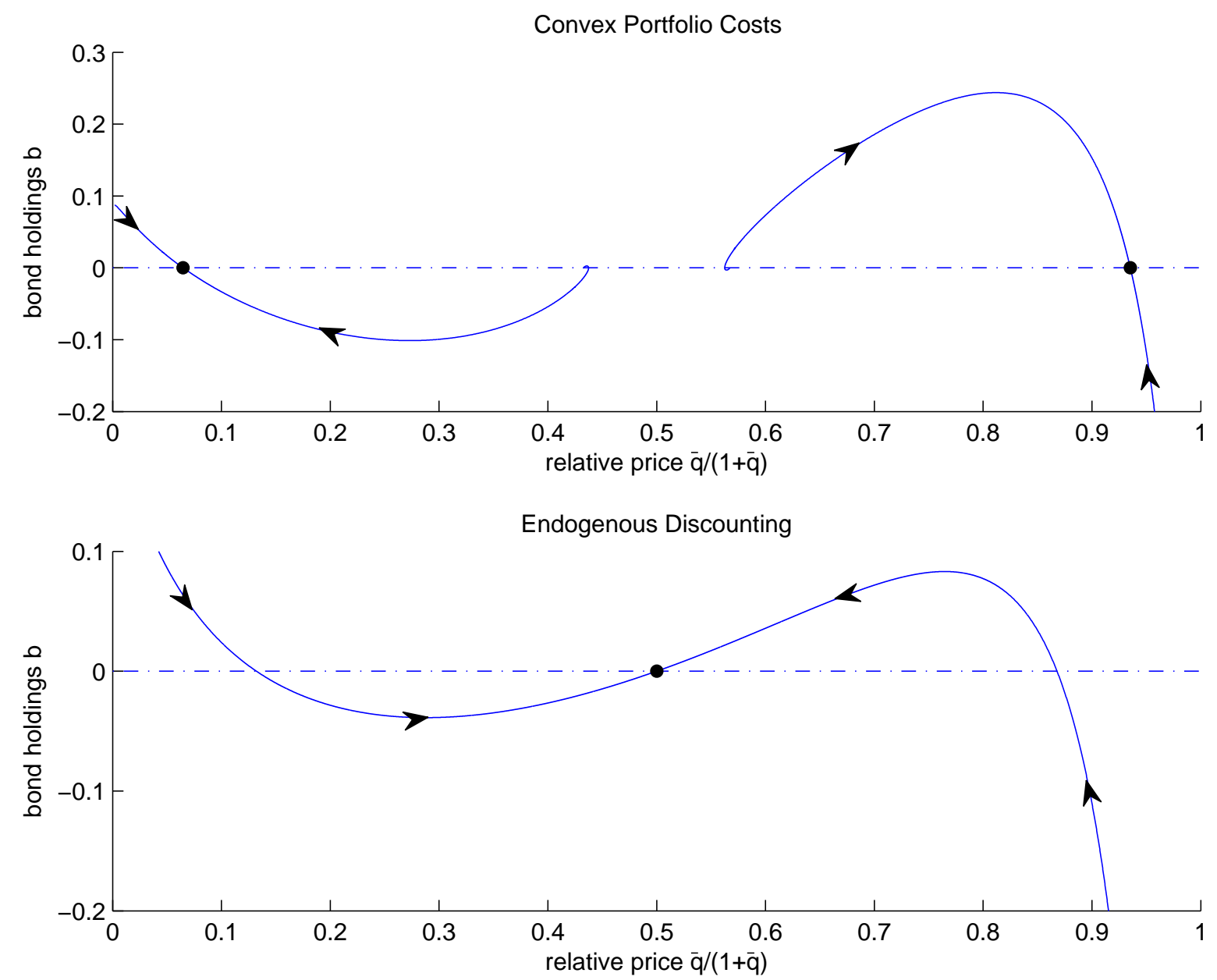
Figure 3: Impulse Responses for Selected Variables: Convex Portfolio Costs
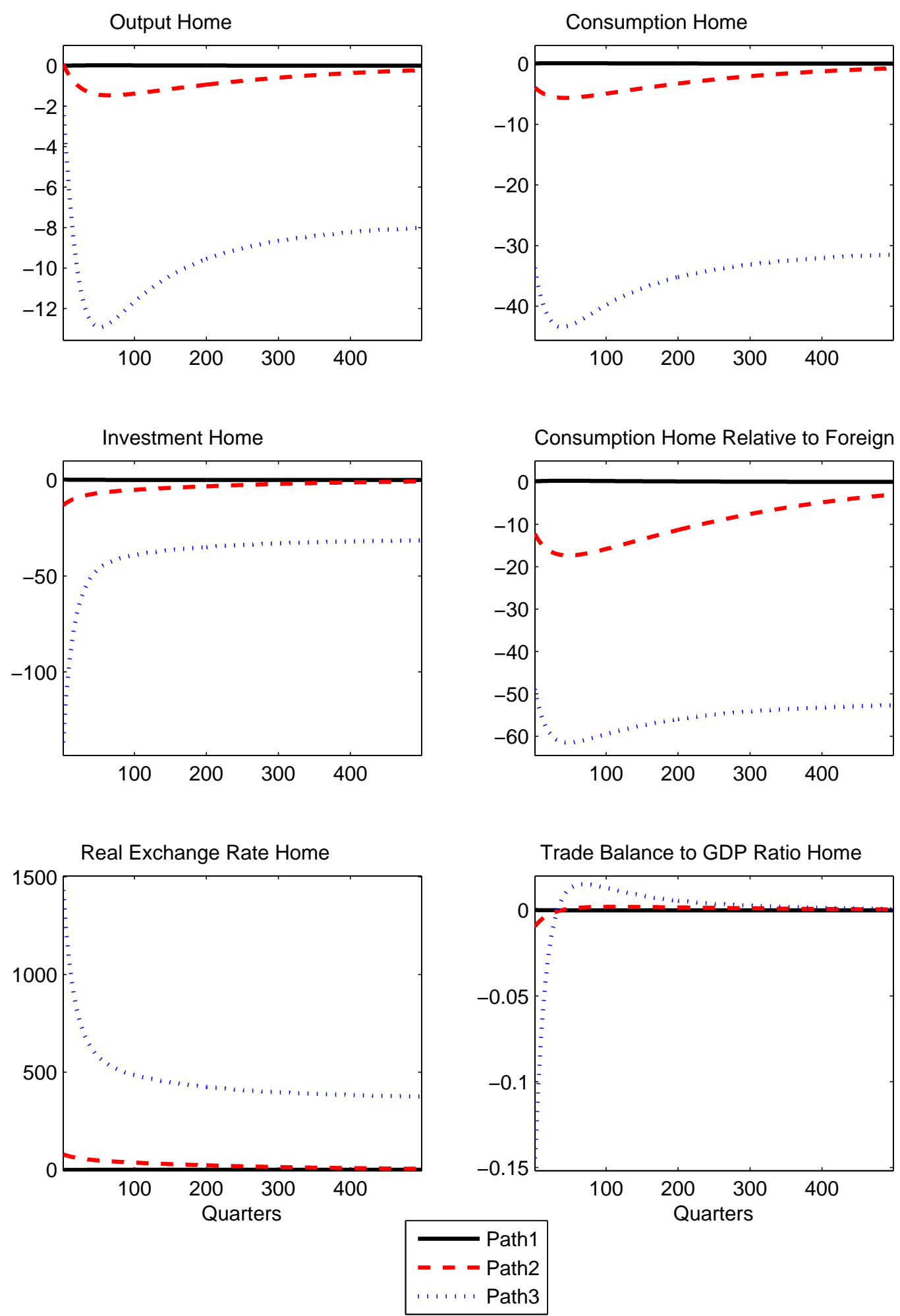
Figure 4: Linear vs Nonlinear Impulse Responses: Path 1
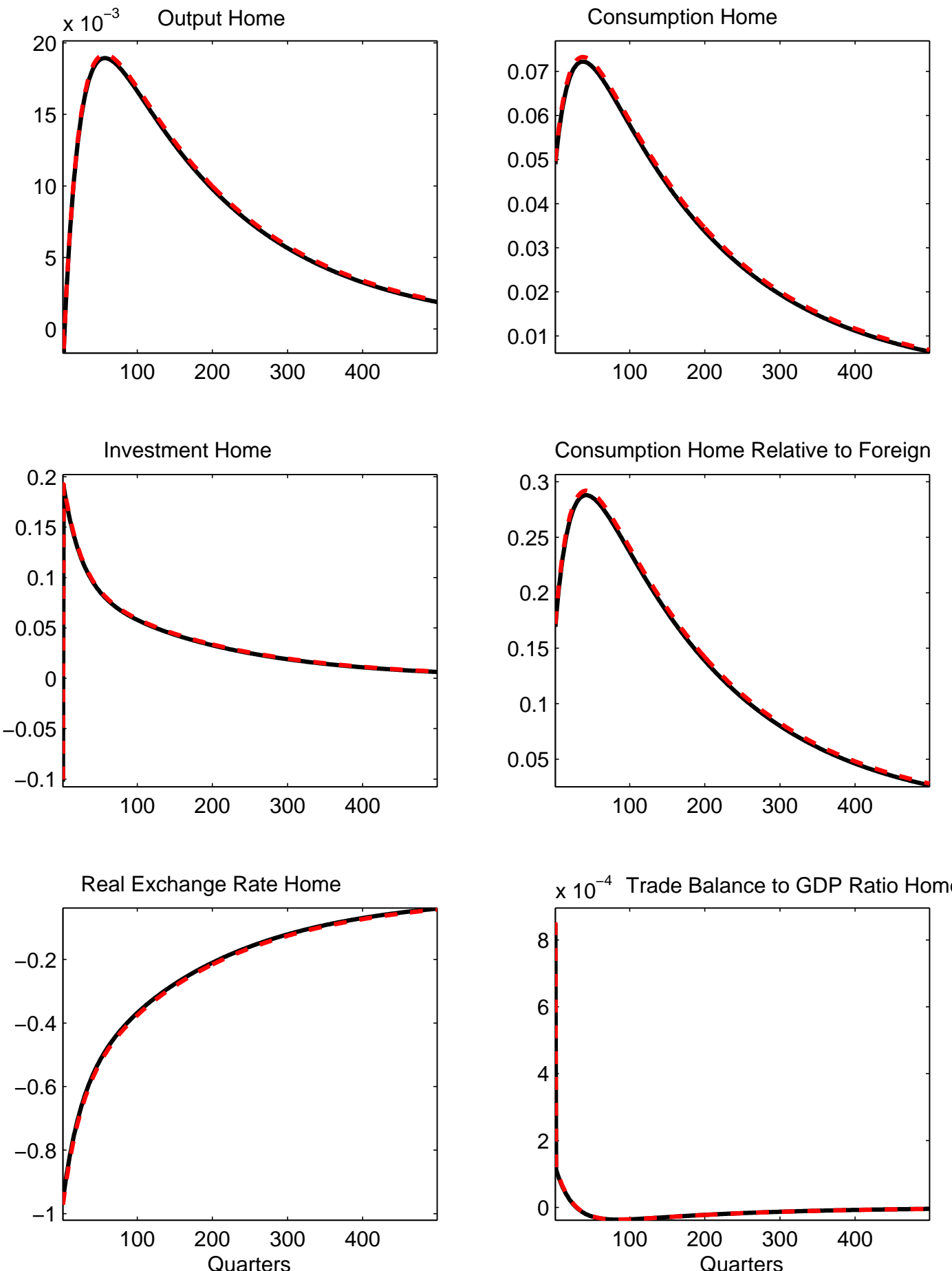

Path1 (nonlinear)

- Path1 (linear) 
Figure 5: Linear vs Nonlinear Impulse Responses: Path 3
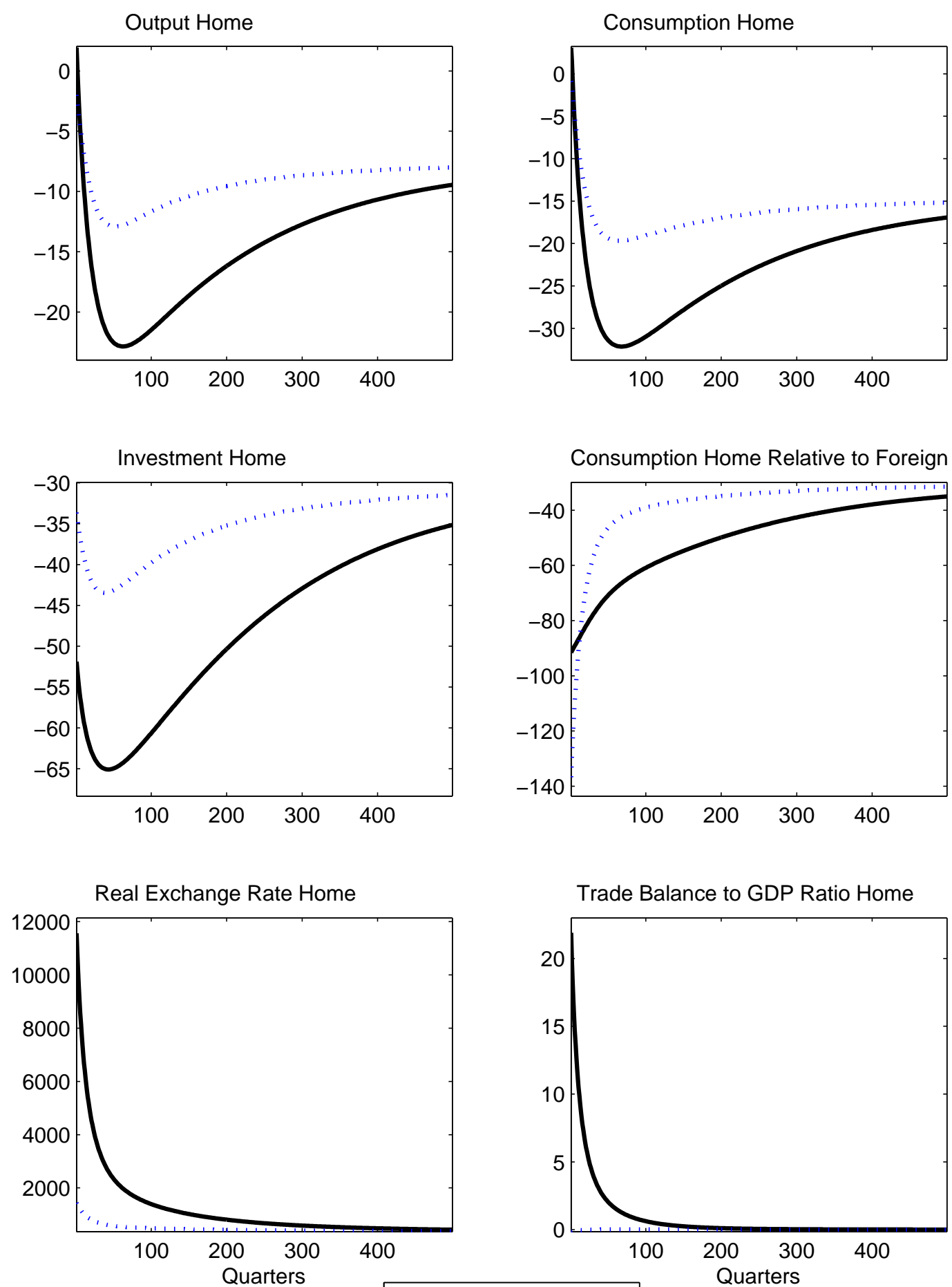

Trade Balance to GDP Ratio Home

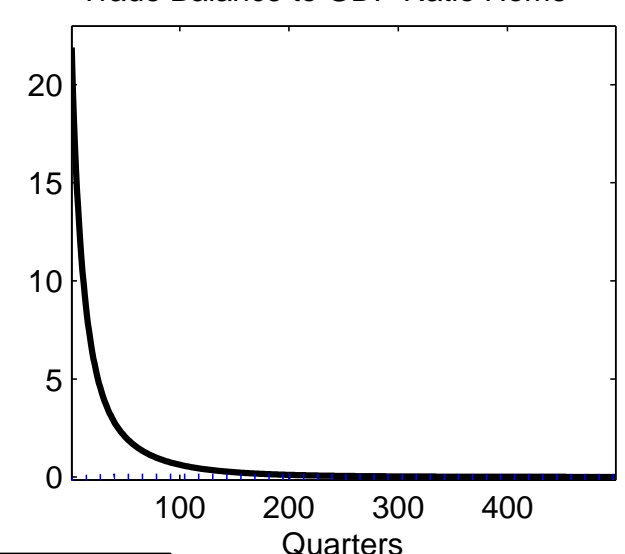

Path3 (nonlinear)

Path3 (linear) 
Figure 6: Impulse Responses for Selected Variables: Endogenous Discounting
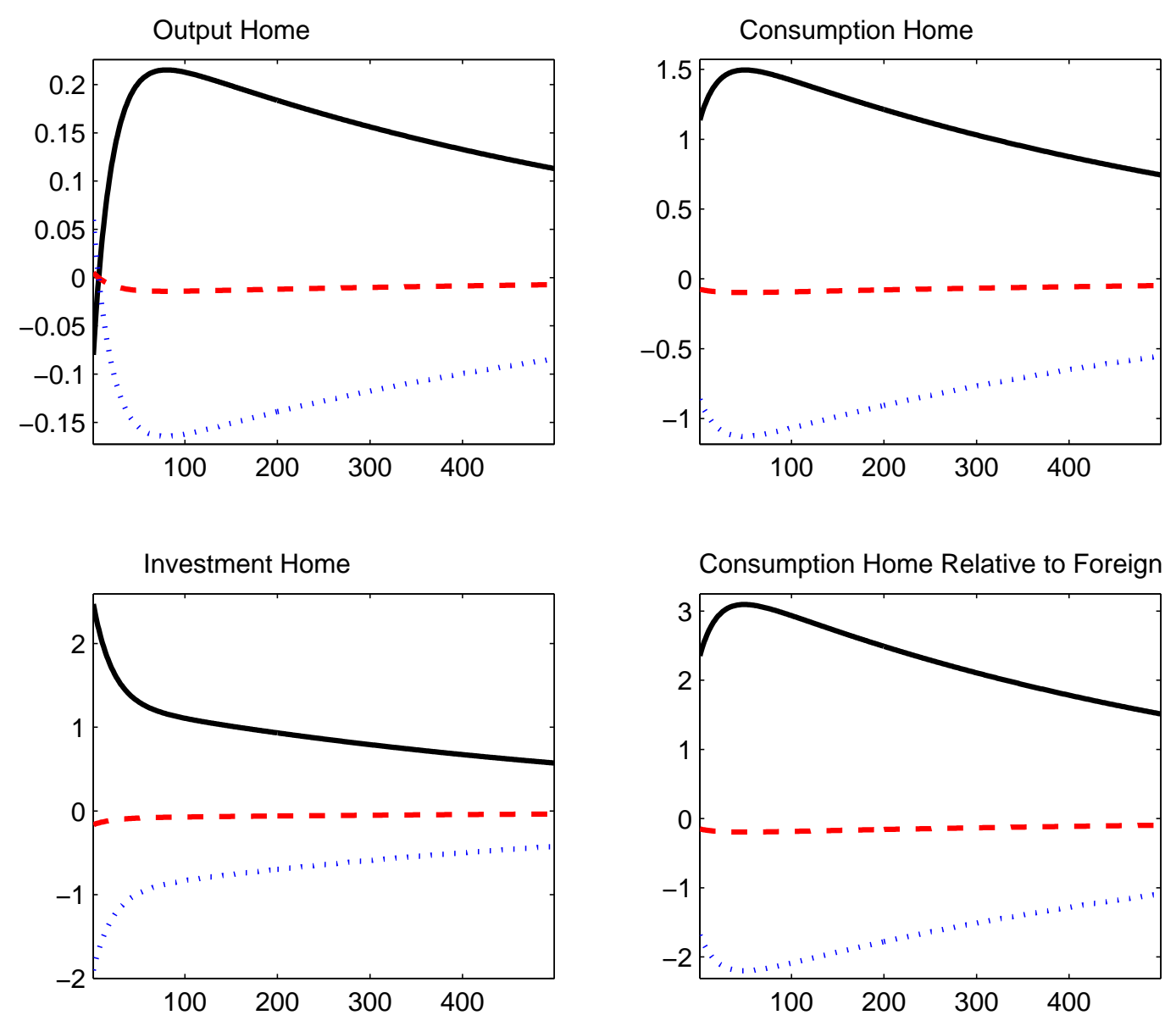

Consumption Home Relative to Foreign

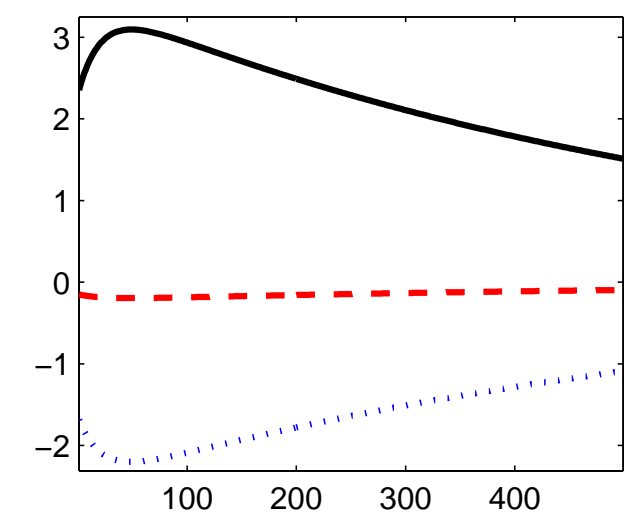

Real Exchange Rate Home

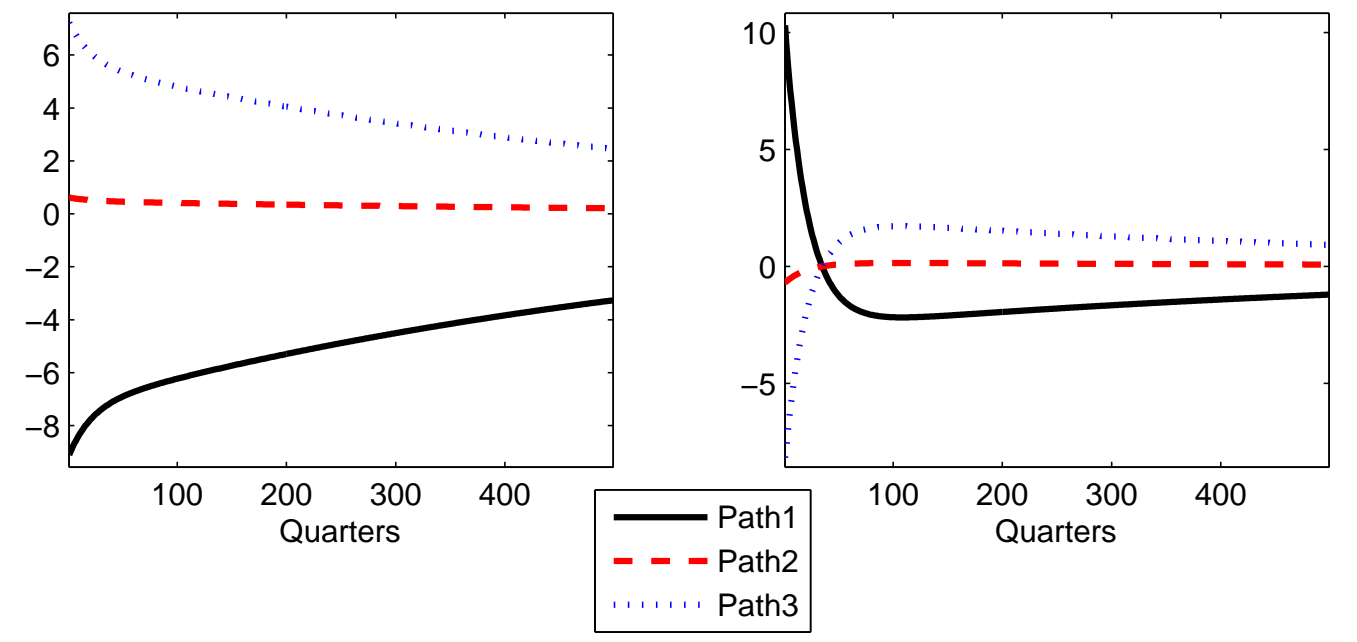


Figure 7: Slope of the Excess Demand Function

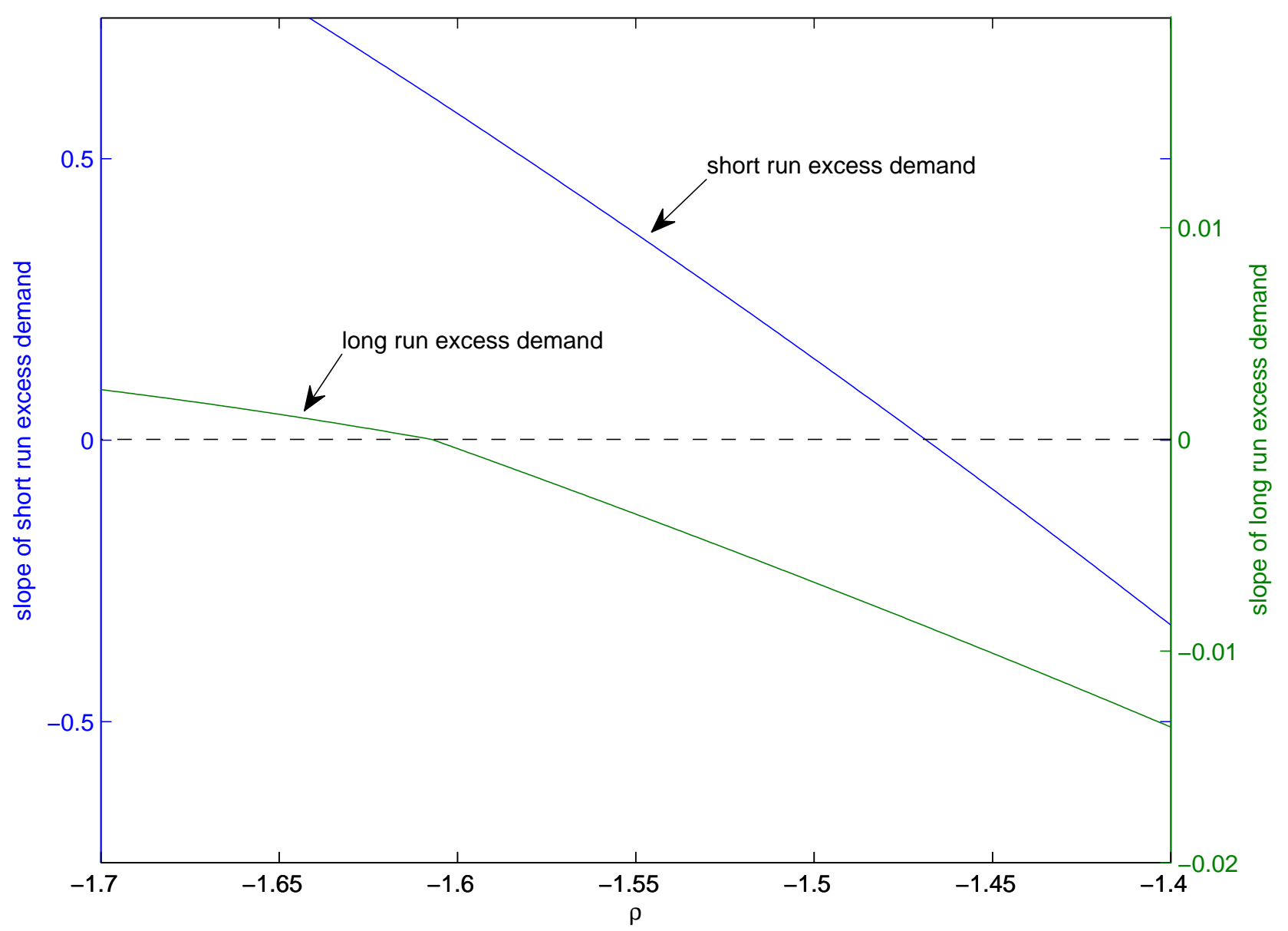


Figure 8: Existence of Equilibrium Paths: Path Comparison
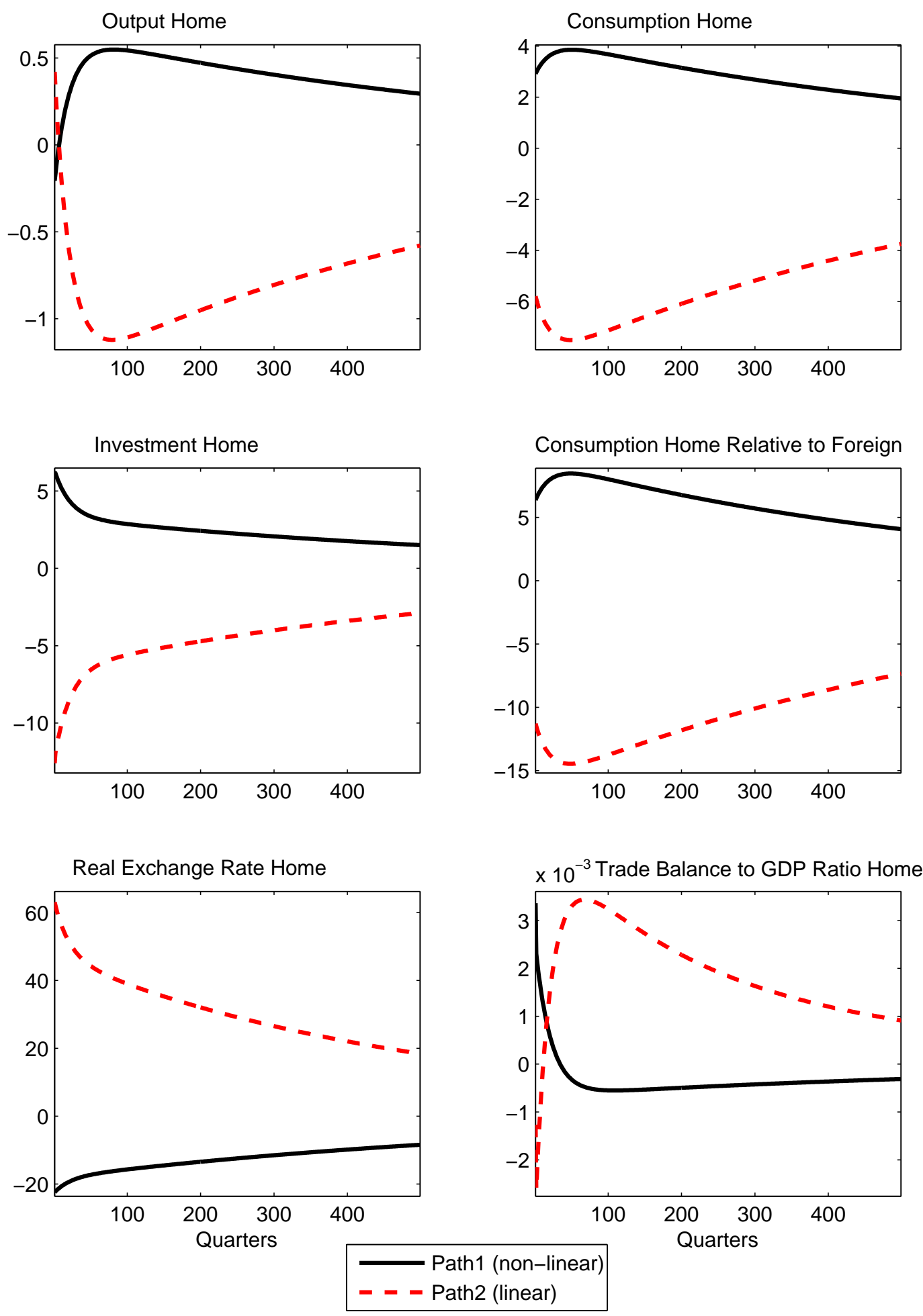
Figure 9: Existence of Equilibrium Paths: Approximation Errors

Errors in Path1 (non-linear)

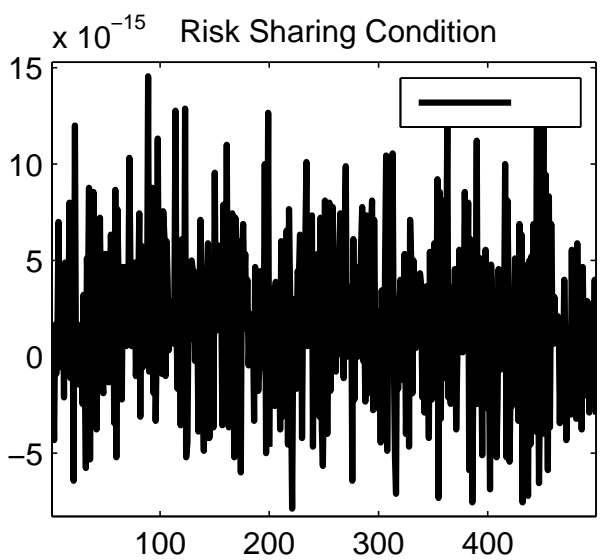

Errors in Path2 (linear)

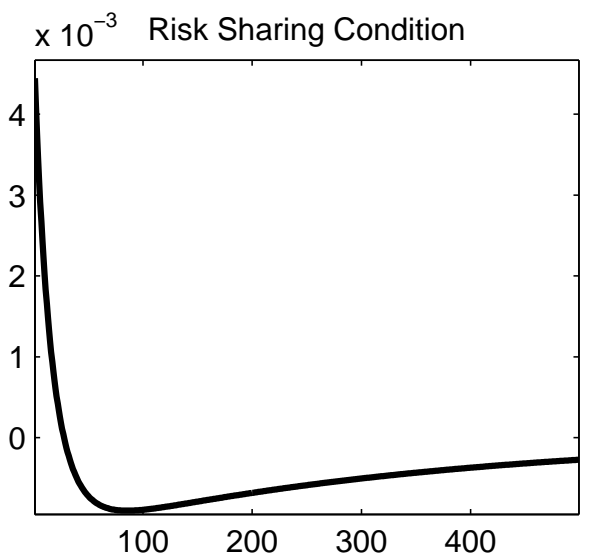

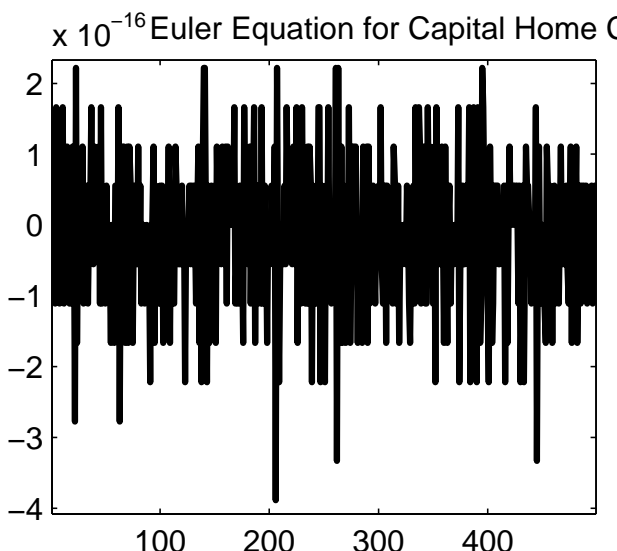
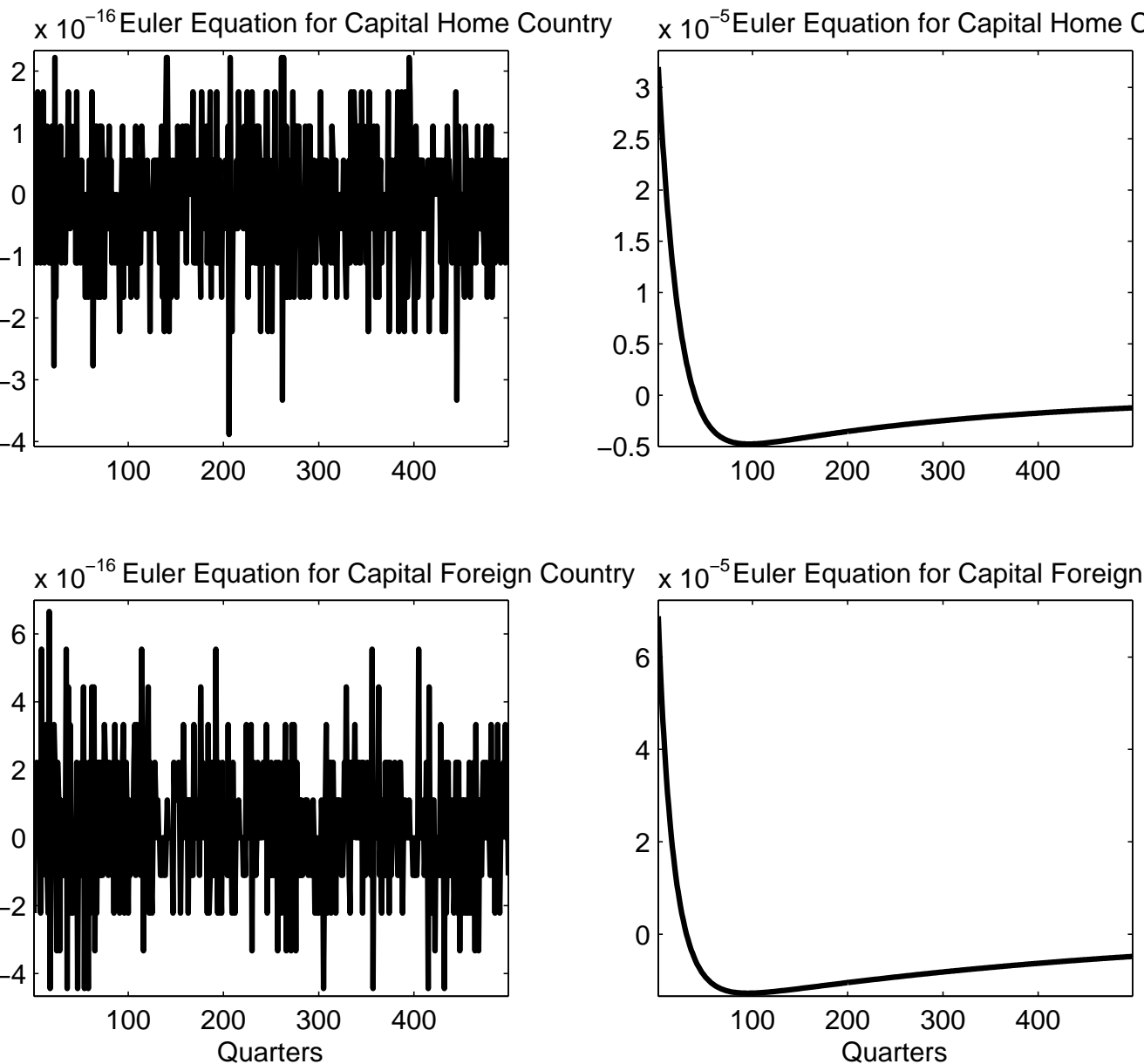


\section{A Appendix: Derivation of the Short- and Long- Run Excess Demand Function}

Preliminaries To derive the slope of the short- and long-run excess demand function with respect to the relative price, $\frac{\partial z_{2 t}}{\partial \bar{q}_{t}}$, the following derivations will be of help. Let $d x_{t}$ denotes the absolute deviation of variable $x$ from its steady state value. Trade is assumed to be balanced in the steady state.

Linearizing equations (18) and (19) delivers expressions for $c_{12}$ and $c_{22}$

$$
\begin{aligned}
\frac{1}{c_{12}} d c_{12 t}= & \left\{\frac{\rho}{\rho-1} \frac{\Phi_{1}^{\prime}(\bar{q}) \bar{q}}{\Phi_{1}(\bar{q})}+\frac{1}{\rho-1}\right\} \frac{1}{\bar{q}} d \bar{q}_{t}+\frac{1}{y_{1}} d y_{1 t} \\
& +\frac{1}{y_{1} \Phi_{1}(\bar{q})}\left[d b_{1 t-1}-\beta d b_{1 t}\right] \\
\frac{1}{c_{22}} d c_{22 t}= & \frac{\rho}{\rho-1} \frac{\Phi_{2}^{\prime}(\bar{q}) \bar{q}}{\Phi_{2}(\bar{q})} \frac{1}{\bar{q}} d \bar{q}_{t}+\frac{1}{y_{2}} d y_{2 t}-\frac{1}{\bar{q} \Phi_{1}(\bar{q}) y_{2}}\left[d b_{1 t-1}-\beta d b_{1 t}\right] .
\end{aligned}
$$

Furthermore, the production function of firms (equation 12) implies

$$
\frac{1}{y_{i}} d y_{i t}=\omega_{l i} \frac{1}{l_{i}} d l_{i t}+\omega_{k i} \frac{1}{k_{i}} d k_{i t-1},
$$

and the capital accumulation constraint (equation 8) delivers

$$
\frac{1}{i_{i}} d i_{i t}=\frac{1}{\delta} \frac{1}{k_{i}} d k_{i t}-\frac{1-\delta}{\delta} \frac{1}{k_{i}} d k_{i t-1} .
$$

From the household's optimal allocation between consumption and leisure, $\frac{U_{l}\left(c_{i}, l_{i}\right)}{U_{c}\left(c_{i}, l_{i}\right)}=$ $-\Phi_{i}(\bar{q}) w_{i}$, and the utility function (23), the labor supply can be approximated by

$$
\frac{1}{l_{i}} d l_{i t}=\frac{1}{1+\chi} \frac{\Phi_{i}^{\prime}(\bar{q}) \bar{q}}{\Phi_{i}(\bar{q})} \frac{1}{\bar{q}} d \bar{q}_{t}+\frac{1}{1+\chi} \frac{1}{y_{i}} d y_{i t}-\frac{\sigma}{1+\chi} \frac{1}{c_{i}} d c_{i t} .
$$

Combining equations (32) to (36) the output deviations can be expressed as

$$
\begin{aligned}
\frac{1}{y_{1}} d y_{1 t} & =\tau_{\bar{q} 1} \frac{\Phi_{1}^{\prime}(\bar{q}) \bar{q}}{\Phi_{1}(\bar{q})} \frac{1}{\bar{q}} d \bar{q}_{t}-\tau_{b 1} \frac{1}{\Phi_{1}(\bar{q}) y_{1}}\left[d b_{1 t-1}-\beta d b_{1 t}\right]+\tau_{i 1} \frac{1}{i_{1}} d i_{1 t}+\tau_{k 1} \frac{1}{k_{1}} k_{1 t-1}, \\
\frac{1}{y_{2}} d y_{2 t} & =\tau_{\bar{q} 2} \frac{\Phi_{2}^{\prime}(\bar{q}) \bar{q}}{\Phi_{2}(\bar{q})} \frac{1}{\bar{q}} d \bar{q}_{t}+\tau_{b 2} \frac{1}{\Phi_{1}(\bar{q}) \bar{q} y_{2}}\left[d b_{1 t-1}-\beta d b_{1 t}\right]+\tau_{i 2} \frac{1}{i_{2}} d i_{2 t}+\tau_{k 2} \frac{1}{k_{2}} k_{2 t-1},
\end{aligned}
$$


where

$$
\begin{aligned}
& \tau_{\bar{q} j}=\frac{\frac{\omega_{l j}}{1+\chi}\left(1-\sigma \frac{\Phi_{j}(\bar{q}) y_{j}}{c_{j}}\right)}{1-\frac{\omega_{l j}}{1+\chi}\left(1-\sigma \frac{\Phi_{j}(\bar{q}) y_{j}}{c_{j}}\right)}, \tau_{b j}=\frac{\frac{\omega_{l j}}{1+\chi} \sigma \frac{\Phi_{j}(\bar{q}) y_{j}}{c_{j}}}{1-\frac{\omega_{l j}}{1+\chi}\left(1-\sigma \frac{\Phi_{j}(\bar{q}) y_{j}}{c_{j}}\right)}, \\
& \tau_{k j}=\frac{\omega_{k j}}{1-\frac{\omega_{l j}}{1+\chi}\left(1-\sigma \frac{\Phi_{j}(\bar{q}) y_{j}}{c_{j}}\right)}, \tau_{i j}=\frac{\frac{\omega_{l j}}{1+\chi} \sigma\left(\frac{\Phi_{j}(\bar{q}) y_{j}}{c_{j}}-1\right)}{1-\frac{\omega_{l j}}{1+\chi}\left(1-\sigma \frac{\Phi_{j}(\bar{q}) y_{j}}{c_{j}}\right)},
\end{aligned}
$$

for $j=1,2$.

Slope of the Excess Demand Function Excess demand for good 2 is given by $z_{2}\left(s^{t}\right)=c_{12}\left(s^{t}\right)+c_{22}\left(s^{t}\right)-y_{2}\left(s^{t}\right)$ with $z_{2}\left(s^{t}\right)=0$ in equilibrium. Linearization of this relationship around a steady state delivers

$$
d z_{2}=d c_{12 t}+d c_{22 t}-d y_{2 t}
$$

Substituting in expressions (32) and (33) and using the facts that $y_{2}=c_{12}+c_{22}$, $\bar{q} c_{12}=c_{21}, \frac{\Phi_{1}^{\prime}(\bar{q}) \bar{q}}{\Phi_{1}(\bar{q})}=-\frac{\bar{q} c_{12}}{y_{1}}$, and $\frac{\Phi_{2}^{\prime}(\bar{q}) \bar{q}}{\Phi_{2}(\bar{q})}=\frac{c_{21}}{\bar{q} y_{2}}$ in any steady state with balanced trade

$$
\begin{aligned}
\frac{1}{c_{12}} d z_{2}= & {\left[-\left(1+\frac{1}{1-\rho} \frac{c_{11}}{c_{21}}\right) \frac{c_{21}}{y_{1}}+\left(1-\frac{1}{1-\rho}\right) \frac{c_{22}}{c_{12}} \frac{c_{12}}{y_{2}}\right] \frac{1}{\bar{q}} d \bar{q}_{t} } \\
& -\frac{1}{\bar{q} \Phi_{1}(\bar{q}) c_{12}}\left(1-\frac{c_{21}}{y_{1}}-\frac{c_{12}}{y_{2}}\right)\left[d b_{1 t-1}-\beta d b_{1 t}\right] \\
& +\frac{1}{y_{1}} d y_{1 t}-\frac{1}{y_{2}} d y_{2 t} .
\end{aligned}
$$

and substituting in the approximations for output

$$
\begin{aligned}
\frac{1}{c_{12}} d z_{2}= & {\left[-\left(1+\frac{1}{1-\rho} \frac{c_{11}}{c_{21}}+\tau_{\bar{q} 1}\right) \frac{c_{21}}{y_{1}}+\left(\left(1-\frac{1}{1-\rho}\right) \frac{c_{22}}{c_{12}}-\tau_{\bar{q} 2}\right) \frac{c_{12}}{y_{2}}\right] \frac{1}{\bar{q}} d \bar{q}_{t} } \\
& -\frac{1}{\bar{q} \Phi_{1}(\bar{q}) c_{12}}\left(1-\left(1-\tau_{b 1}\right) \frac{c_{21}}{y_{1}}-\left(1-\tau_{b 2}\right) \frac{c_{12}}{y_{2}}\right)\left[d b_{1 t-1}-\beta d b_{1 t}\right] \\
& +\frac{\tau_{i 1}}{i_{1}} d i_{1 t}-\frac{\tau_{i 2}}{i_{2}} d i_{2 t}+\frac{\tau_{k 1}}{k_{1}} k_{1 t-1}-\frac{\tau_{k 2}}{k_{2}} k_{2, t-1} .
\end{aligned}
$$

In the case of a static endowment economy as in Section $2, \omega_{l i}=0$ and $\operatorname{sign}\left(\frac{\partial z_{2 t}}{\partial \bar{q}_{t}}\right)$ is given by the sign of $\left[-\left(1+\frac{1}{1-\rho} \frac{c_{11}}{c_{21}}\right) \frac{c_{21}}{y_{1}}+\left(\left(1-\frac{1}{1-\rho}\right) \frac{c_{22}}{c_{12}}\right) \frac{c_{12}}{y_{2}}\right] \cdot{ }^{25}$ For the above

\footnotetext{
${ }^{25}$ In the endowment economy, the contemporaneous decision on bond holdings does not affect the slope of the excess demand function in the short run. This is different from the economy with endogenous capital.
} 
calibration, the steady state allocations and prices in the equilibrium with $\bar{q}=1$, do not depend on the value of the trade elasticity of substitution $\varepsilon=\frac{1}{1-\rho}$. Therefore, it can easily be seen that the slope of the excess demand function becomes positive if $\varepsilon$ is sufficiently low and multiple equilibria appear.

In the dynamic production economy with flexible labor and capital, additional terms determine $\operatorname{sign}\left(\frac{\partial z_{2 t}}{\partial \bar{q}_{t}}\right)$. With flexible labor $\tau_{\bar{q} 1}$ and $\tau_{\bar{q} 2}$ are different from zero and the threshold value of $\rho$ for which $\frac{\partial z_{2 t}}{\partial \bar{q}_{t}}$ switches sign can be higher or lower depending on the relative magnitudes of the remaining parameters. The contemporaneous choices for investment (or capital) and bond holdings also affect the relative price through the equilibrium requirement of zero excess demand. Since bond holdings, foreign and domestic capital are the three endogenous state variables of the model, $d i_{1 t}, d i_{2 t}, d b_{t}$, and $\bar{q}_{t}$ can be expressed as functions of $d b_{1 t-1}, d k_{1 t-1}$, and $d k_{2 t-1} \cdot{ }^{26}$

To obtain the sign of $\frac{\partial z_{2 t}}{\partial \bar{q}_{t}}$ it is key to rewrite the decision rules for $d i_{1 t}, d i_{2 t}, d b_{t}$ in terms of $\bar{q}_{t}$ using the decision rule for $\bar{q}_{t}$ and substitute the results into (37). Let $D(x, y)$ denote the coefficient on the state variable $x$ in the (linear) decision rule for variable $y$. The sign of $\frac{\partial z_{2 t}}{\partial \bar{q}_{t}}$ is positive in the short run if

$$
\begin{aligned}
& -\left(1+\frac{1}{1-\rho} \frac{c_{11}}{c_{21}}+\tau_{\bar{q} 1}\right) \frac{c_{21}}{y_{1}}+\left(\left(1-\frac{1}{1-\rho}\right) \frac{c_{22}}{c_{12}}-\tau_{d \bar{q} 2}\right) \frac{c_{12}}{y_{2}} \\
& -\frac{1-\left(1-\tau_{b 1}\right) \frac{c_{21}}{y_{1}}-\left(1-\tau_{b 2}\right) \frac{c_{12}}{y_{2}}}{\bar{q} \Phi_{1}(\bar{q}) c_{12}} \frac{D(b, b)}{D(d, \bar{q})} \\
& +\frac{\tau_{i 1}}{i_{1}} \frac{D\left(b, i_{1}\right)}{D(d, \bar{q})}-\frac{\tau_{i 2}}{i_{2}} \frac{D\left(b, i_{2}\right)}{D(d, \bar{q})}<0 .
\end{aligned}
$$

In the short run the capital stock is fixed and bond holdings effect the relative price through their reallocative effects of purchasing power. ${ }^{27}$

\footnotetext{
${ }^{26}$ The decision rules for the endogenous variables in terms of the state variables can be found by using standard techniques for solving linearized rational expectations models.

${ }^{27}$ The policy functions depend on the assumption that induces a stationary net foreign asset position. Hence, the exact value of the threshold and the occurance of multiple equilibria differ between the model with endogenous discounting and the model with convex portfolio costs.
} 
By contrast, the sign of $\frac{\partial z_{2 t}}{\partial \bar{q}_{t}}$ for the long run is affected by the full flexibility of the capital stock in the long run. At the same time, bond holdings are restricted to be zero. Hence, $\operatorname{sign}\left(\frac{\partial z_{2 t}}{\partial \bar{q}_{t}}\right)>0$ if

$$
\begin{aligned}
& -\left(1+\frac{1}{1-\rho} \frac{c_{11}}{c_{21}}+\tau_{\bar{q} 1}\right) \frac{c_{21}}{y_{1}}+\left(\left(1-\frac{1}{1-\rho}\right) \frac{c_{22}}{c_{12}}-\tau_{d \bar{q} 2}\right) \frac{c_{12}}{y_{2}} \\
& +\left(\tau_{i 1}+\tau_{k 1}\right) \omega_{l 1} \frac{1+\chi}{\chi+\sigma}-\left(\tau_{i 2}+\tau_{k 2}\right) \omega_{l 2} \frac{1+\chi}{\chi+\sigma}<0 .
\end{aligned}
$$

While the slope of the excess demand function is the same in the short and the long run for an endowment economy, equations (38) and (39) reveal that these slopes can be very different in a model with endogenous capital an international bond holdings. Figure 7 plots expressions (38) and (39) as functions of $\rho$ at the steady state with $\bar{q}=1$ in the model with endogenous discounting. 